\title{
The inferior vena cava: anatomical variants and acquired pathologies
}

\author{
Simon J. Li ${ }^{1 *} \mathbb{B}$, Jean Lee ${ }^{1}$, Jonathan Hall ${ }^{1,2}$ and Tom R. Sutherland ${ }^{1,3}$
}

\begin{abstract}
The inferior vena cava (IVC) is the largest vein in the body, draining blood from the abdomen, pelvis and lower extremities. This pictorial review summarises normal anatomy and embryological development of the IVC. In addition, we highlight a wide range of anatomical variants, acquired pathologies and a common pitfall in imaging of the IVC. This information is essential for clinical decision making and to reduce misdiagnosis.
\end{abstract}

Keywords: Anatomical variations, Embryology, Inferior vena cava (IVC), Thrombus, Tumour

\section{Teaching points}

- IVC anomalies are the result of abnormal persistence or regression of embryological veins.

- Recurrent pulmonary embolism following routine infrarenal IVC filter placement should raise suspicion of a duplicated IVC.

- Absent/Interrupted IVC should be suspected in young patients with iliofemoral DVT.

- IVC variants and dilated collateral veins can be mistaken for malignancy.

- Tumour thrombus is differentiated from bland thrombus by filling defect enhancement, vessel lumen expansion and contiguity with the mass.

- Tumour thrombus extent is a key determinant of prognosis and surgical management, particularly in renal cell carcinoma.

\section{Introduction}

The inferior vena cava (IVC) is the main conduit for venous return from the pelvis, abdominal viscera and lower extremities. A comprehensive understanding

\footnotetext{
*Correspondence: dr.simonjli@gmail.com

${ }^{1}$ Medical Imaging Department, St Vincent's Hospital Melbourne, 41

Victoria Parade, Fitzroy, VIC 3065, Australia

Full list of author information is available at the end of the article
}

of IVC anatomy, congenital variants and pathology is instrumental to accurate diagnosis and management. In this review, we discuss normal anatomy, embryogenesis and present illustrated cases of congenital anomalies of the IVC including duplicated IVC, left-sided IVC, absent infrarenal IVC and interrupted IVC with azygos continuation. Diseases involving the IVC can be diagnostically challenging, with computed tomography $(\mathrm{CT})$ and magnetic resonance imaging (MRI) playing key roles in characterising malignancy, tumour extent, caval wall invasion and bland thrombus. This information is crucial for staging and surgical planning. Lastly, we discuss the imaging pitfall of mixed artefact masquerading as thrombus.

\section{Normal IVC anatomy}

The IVC is a large retroperitoneal vein draining the lower extremities, pelvic and abdominal viscera to the right atrium of the heart. It is typically formed by the confluence of the right and left common iliac veins behind the right common iliac artery at the level of the fifth lumbar vertebra. The IVC ascends along the right side of the vertebral column behind the duodenum, portal vein and liver to pierce the diaphragmatic central tendon at the caval opening at the level of the eighth thoracic vertebra. This is followed by a short intra-thoracic course prior to terminating at the right atrium.

As it ascends, it receives many tributaries including paired third and fourth lumbar veins, the right gonadal 
vein, paired renal veins, the right suprarenal vein, paired inferior phrenic veins and three hepatic veins. There can be variations to these tributaries such as hepatic accessory veins, the right gonadal vein draining into a right renal vein, or a right lumbar azygos vein draining first and second lumbar veins [1-4]. Lastly, the azygos venous system supplies collateral circulation between the superior vena cava (SVC) and IVC.

\section{IVC embryology}

The IVC is formed by a complex process of fusion and subsequent regression of embryological veins, namely the posterior cardinal, subcardinal, supracardinal and vitelline veins. In fourth week of embryological development, the right and left horns of the sinus venosus receive paired common cardinal, umbilical and vitelline veins draining blood from general tissue, the placenta and yolk sac, respectively (Fig. 1a) [5, 6].

During the sixth week of gestation, paired posterior cardinal veins are the dominant vessels carrying blood from the caudal portion of the embryo to the common cardinal vein, and later persist as the mature common iliac veins, anastomosing to form the confluence of left and right common iliac veins in the mature venous system [5, 7]. Proximally, paired vitelline and umbilical veins form the hepatic sinusoidal network, including left and right hepatic veins. As the yolk sac and proximal umbilical veins regress, the cranial aspect of the vitelline veins becomes paired hepatocardiac channels, with the right hepatocardiac channel persisting to become the hepatic segment of the IVC [6].

In the following two weeks of foetal development, paired subcardinal and supracardinal veins emerge as dominant tributaries, forming multiple channels draining into the posterior cardinal veins (Fig. 1b) [5]. The subcardinal veins form ventromedial to the posterior cardinal veins, while the supracardinal veins originate dorsomedial to the posterior cardinal veins [7]. Significant anastomotic networks are formed between paired subcardinal veins (intersubcardinal anastomosis) and between supracardinal and subcardinal vessels (suprasubcardinal anastomoses). The proximal posterior cardinal veins subsequently regress, while metanephric kidneys ascend to connect with the suprasubcardinal anastomoses [8]. The intersubcardinal anastomosis forms the left renal vein and in combination with the suprasubcardinal anastomoses contributes to the renal segment of the IVC [9].

At the same time, the cranial end of the right subcardinal vein forms the suprarenal segment of the IVC and fuses with the developing hepatic IVC [9]. Gonadal and suprarenal veins are also derived from the subcardinal veins [6]. The caudal left supracardinal vein and left subcardinal veins regress, establishing right-sided dominance. Paired supracardinal veins and their anastomosis

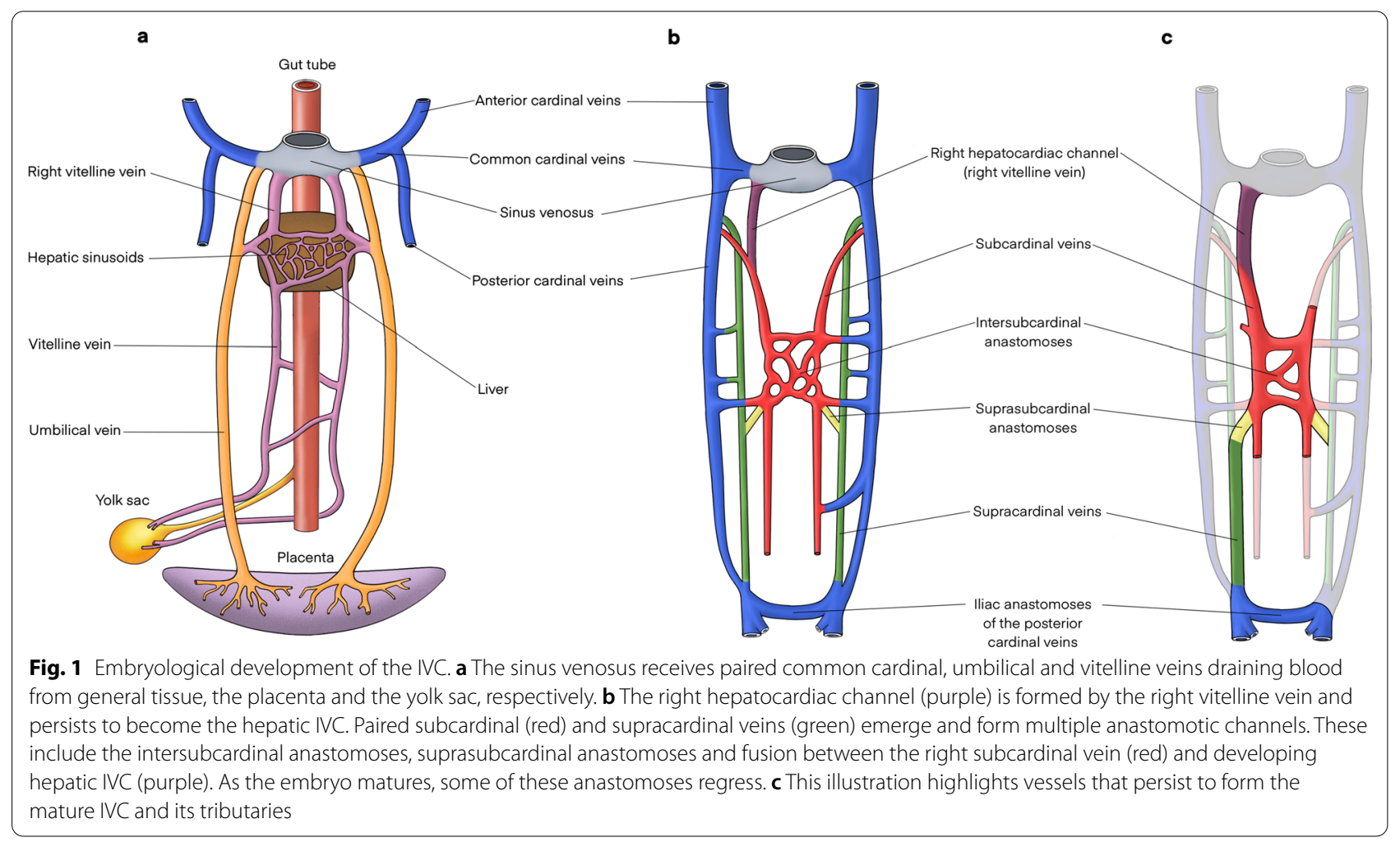


extend above the diaphragm to become the azygos and hemiazygos veins [5, 7]. Caudally, the right supracardinal vein persists as the infrarenal IVC, communicating with the paired iliac veins (Fig. 1c) [6].

In summary, the mature IVC is composed of infrarenal (right supracardinal vein), renal (right suprasubcardinal and intersubcardinal anastomoses), suprarenal/infrahepatic (right subcardinal vein) and hepatic (vitelline veins) segments. Posterior cardinal veins persist as paired common iliac veins, whilst the supracardinal veins contribute to the azygos venous system (Fig. 2).

\section{Anatomical variants}

IVC anatomical variants primarily result from abnormal regression or persistence of embryological veins [7]. Although most anomalies are asymptomatic incidental findings, they can cause lower extremity venous insufficiency, deep vein thrombosis, pelvic congestion syndrome and affect planning of vascular procedures [10-17]. The most common anomalies include duplicated IVC, left-sided IVC and interruption of the IVC.

\section{Duplicated IVC}

A duplicated IVC is formed by an abnormal persisting left supracardinal vein, resulting in duplicated infrarenal IVC segments (Fig. 3). This variant has a prevalence of $0.2-3 \%$ [18]. The common iliac veins typically drain to

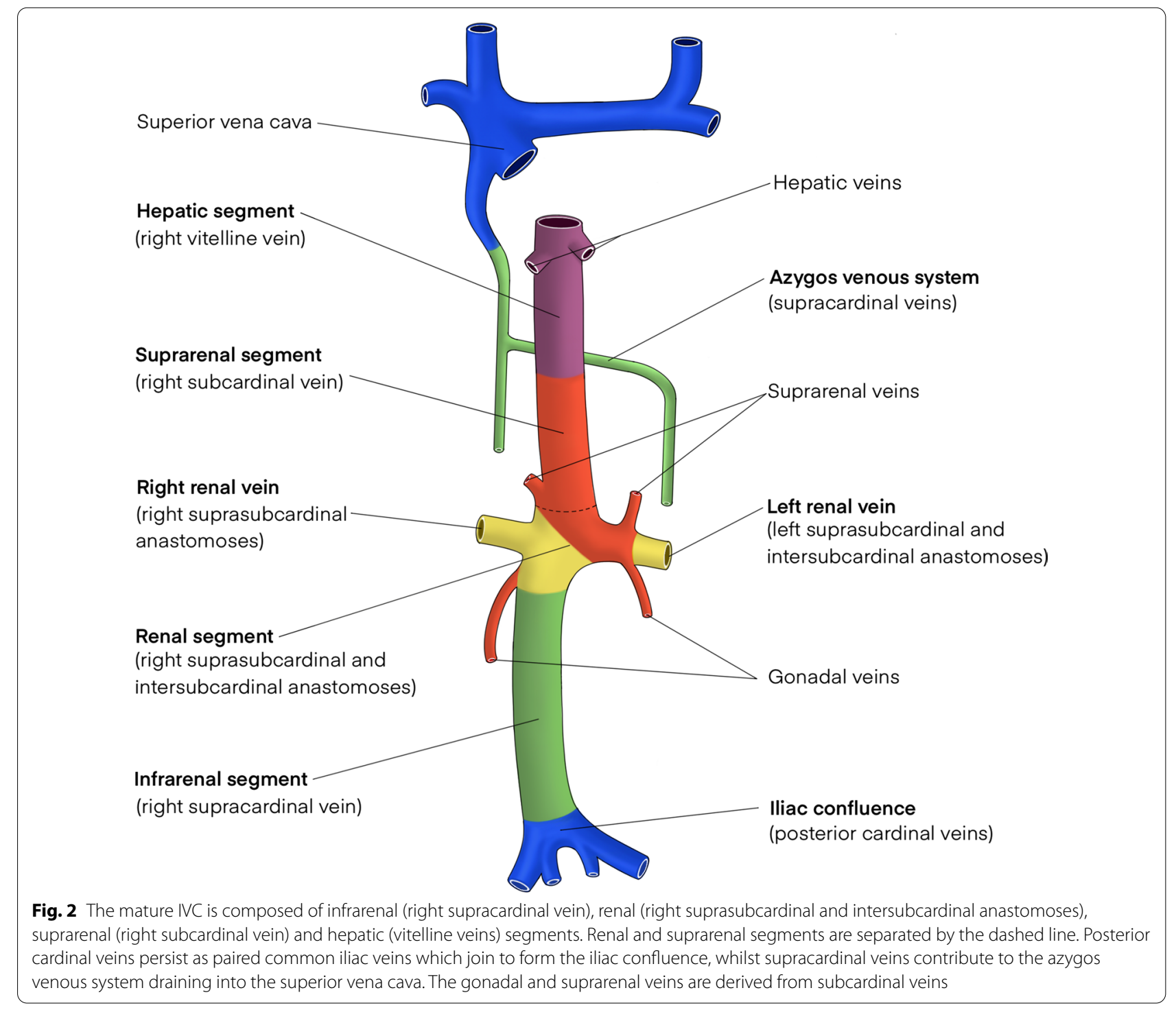



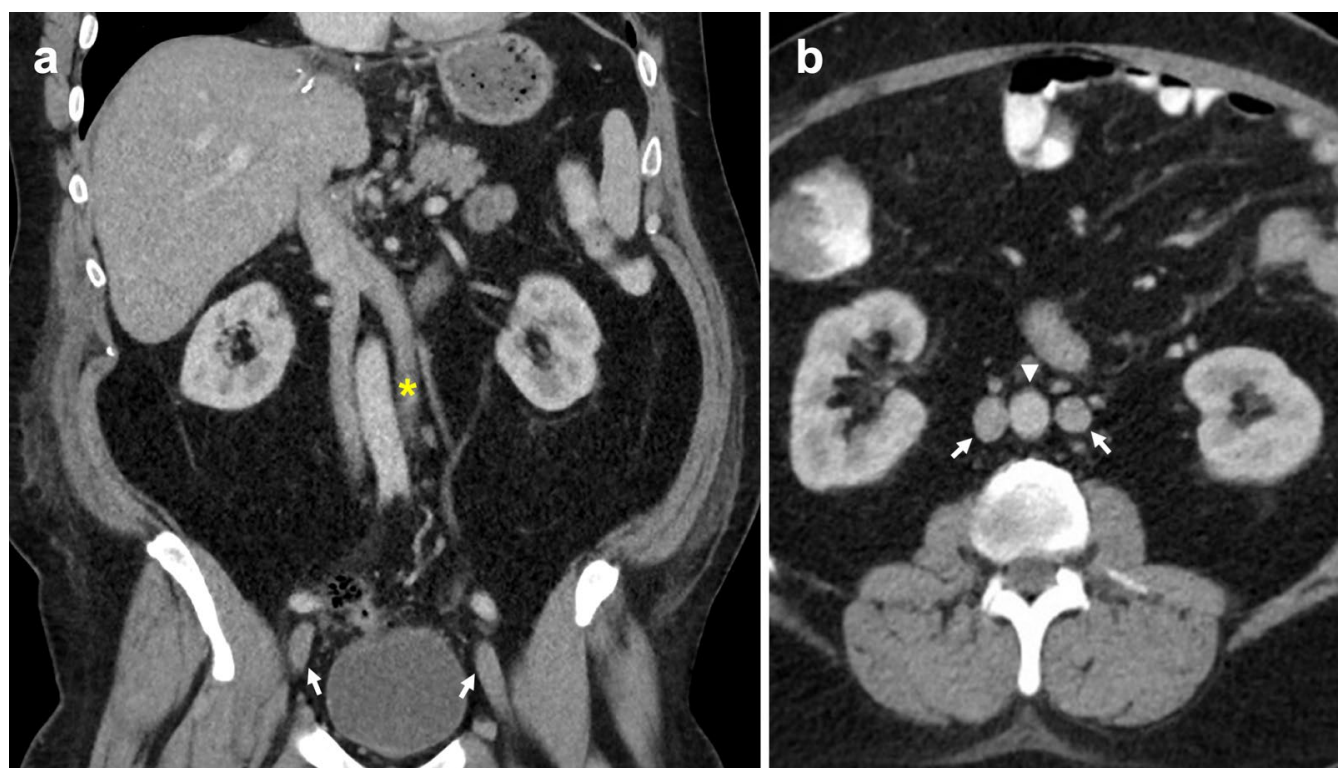

Fig. 3 Duplicated IVC with symmetrical caliber. a Contrast-enhanced coronal CT shows a duplicated IVC (asterisk) with symmetrical caliber draining into the suprarenal IVC. Bilateral external iliac veins (arrows) both drain into cavae on their respective sides. $\mathbf{b}$ Axial CT image shows the paired IVC trunks (arrows) positioned on either side of the abdominal aorta (arrowhead)

their respective sides, with the left infrarenal IVC joining the left renal vein, which in turn crosses to join the orthotopic suprarenal IVC. Some studies subclassify this anomaly by differences in calibre of the duplicated infrarenal IVC segments [19]. In addition, a bridging vein may connect the common iliac veins at the inferior origin
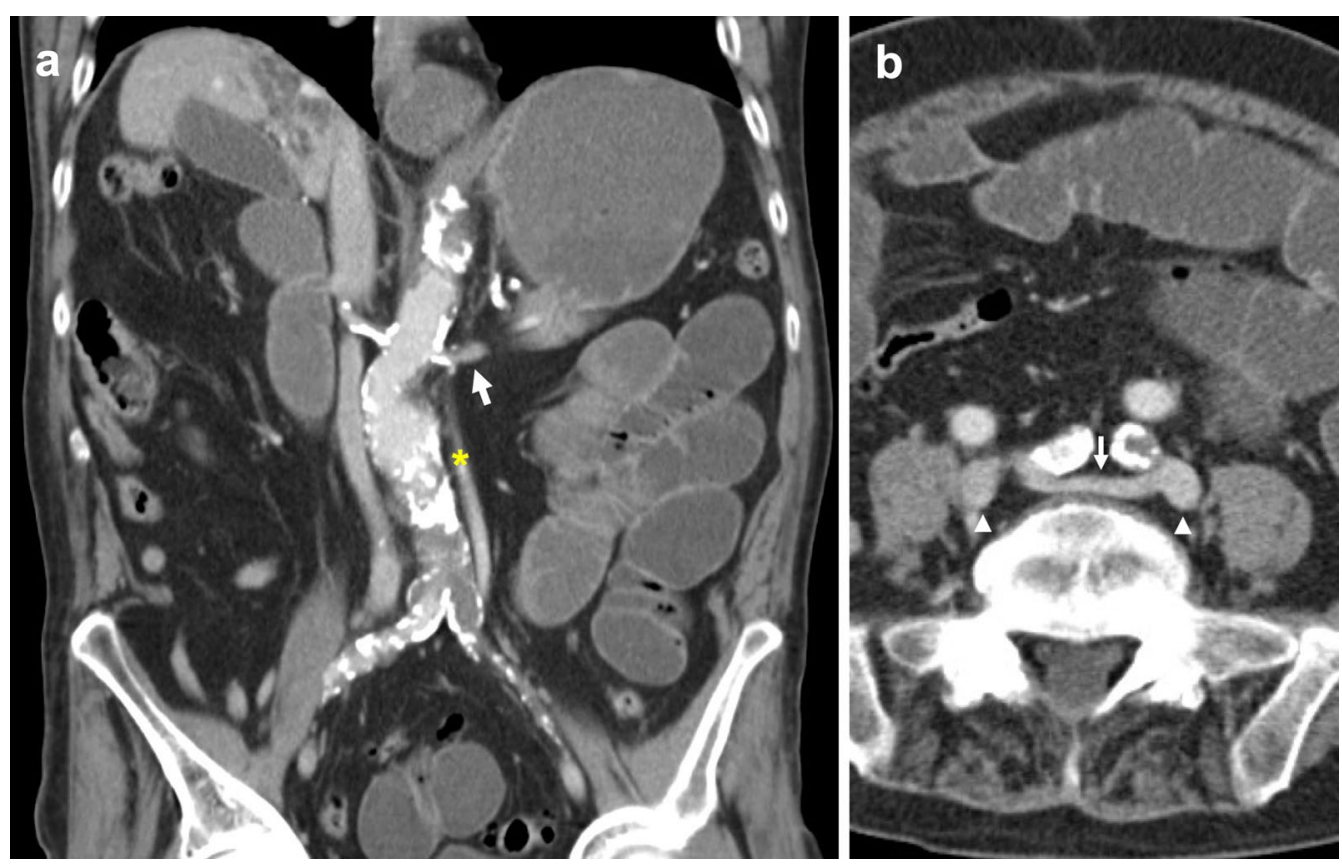

Fig. 4 Duplicated IVC with asymmetrical caliber and bridging vein. a Contrasted-enhanced coronal CT shows a duplicated IVC (asterisk) of smaller caliber compared to the orthotopic IVC, that approaches and subsequently drains into the left renal vein (arrow). b Axial CT image shows a bridging vein (arrow) connecting paired common iliac veins (arrowheads) positioned anterior to the $L 4$ vertebral body and posterior to common iliac arteries 

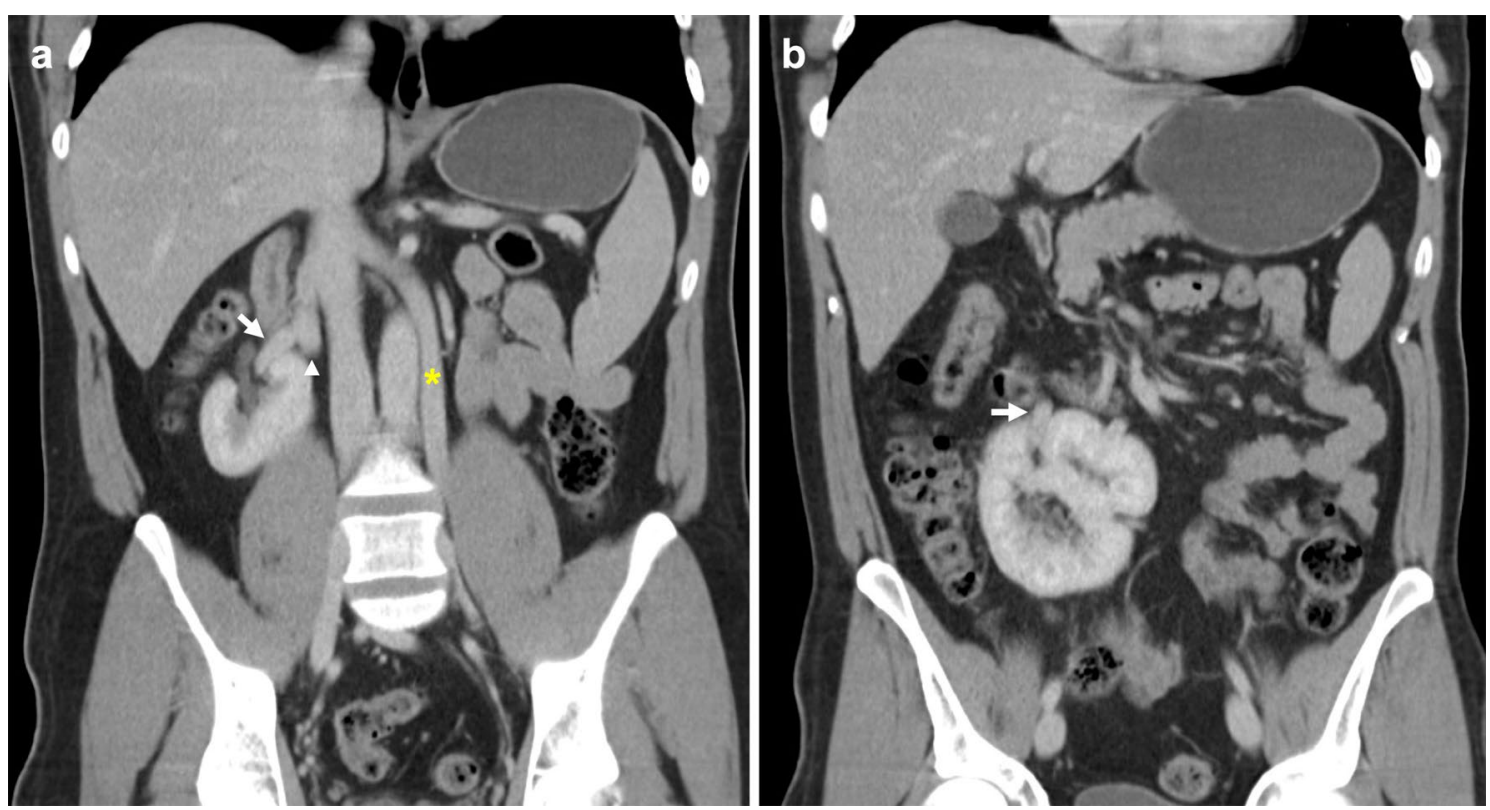

Fig. 5 Duplicated IVC with right-sided crossed fused renal ectopia. a Coronal CT image shows a duplicated IVC (asterisk) crossing the midline to drain into the right-sided suprarenal IVC. The right renal vein (arrow) and vein of the left ectopic kidney (arrowhead) join before draining into the orthotopic IVC. b Coronal CT demonstrates the right-sided crossed fused renal ectopia and its renal vein (arrow)

of the duplicated IVC (Fig. 4) [20]. Rarely, the duplicated segment can continue as the hemiazygos vein and drain directly into the superior vena cava $[21,22]$. Case reports of association with retrocaval ureters, horseshoe kidneys and malrotation of the gut have been described
[23-25]. In this review, we present a rarely described case of duplicated IVC and crossed renal ectopia with both renal veins draining into the orthotopic IVC (Fig. 5) [26]. A duplicated IVC can also be mistaken for adenopathy, or a lymph nodes if its tubular nature is not recognised
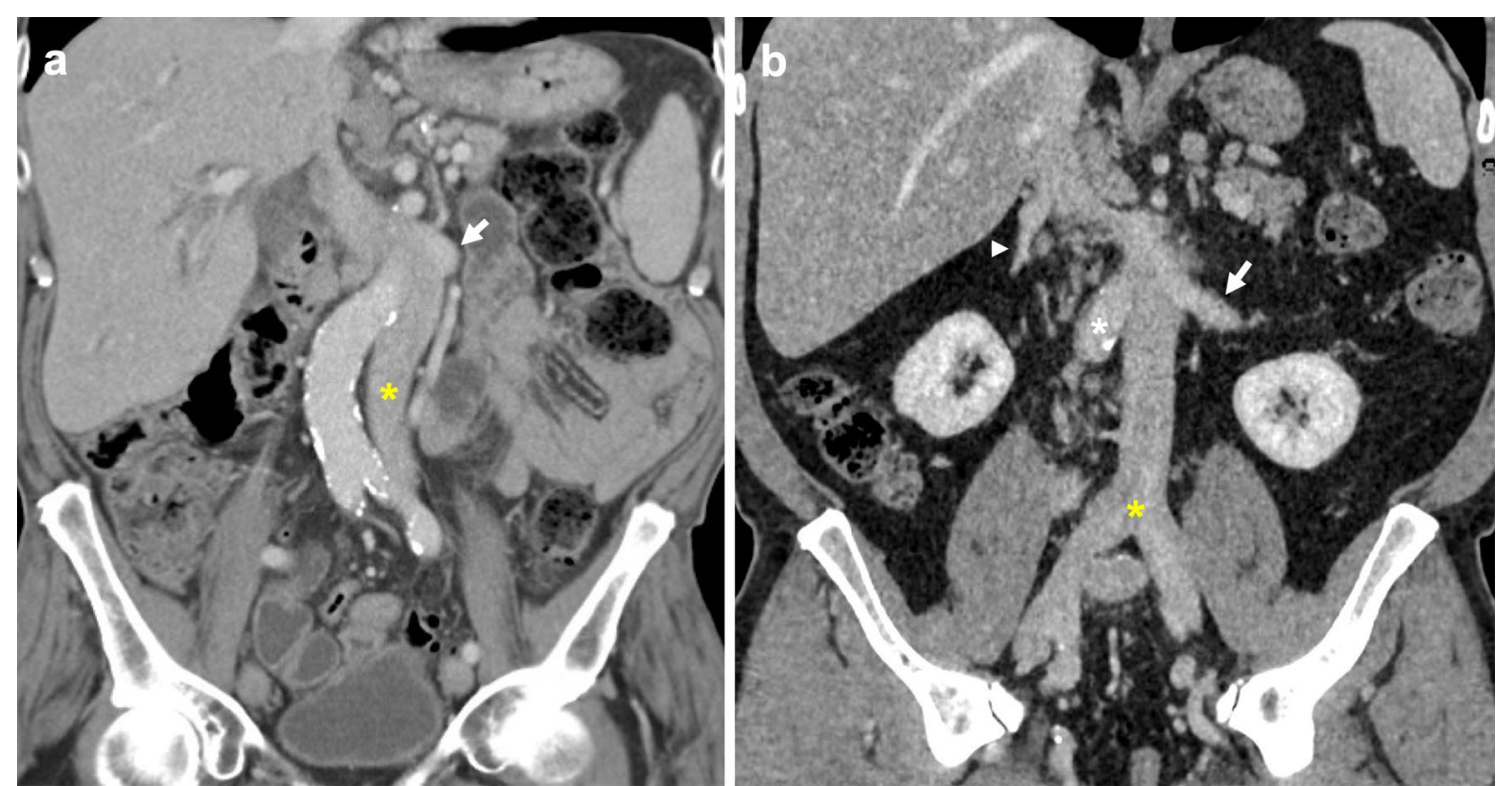

Fig. 6 Left-sided IVC. a Coronal CT image shows a non-enhanced left-sided IVC (asterisk) draining into an enhanced left renal vein which connects to the hepatic IVC. $\mathbf{b}$ Coronal CT image of a second case demonstrates a typical confluence of common iliac veins (yellow asterisk) forming the infrarenal IVC on the left side of the aorta (white asterisk) to join the left renal vein (arrow) which drains into the orthotopic IVC. The proximal right renal vein (arrowhead) is also pictured draining into the suprarenal IVC 

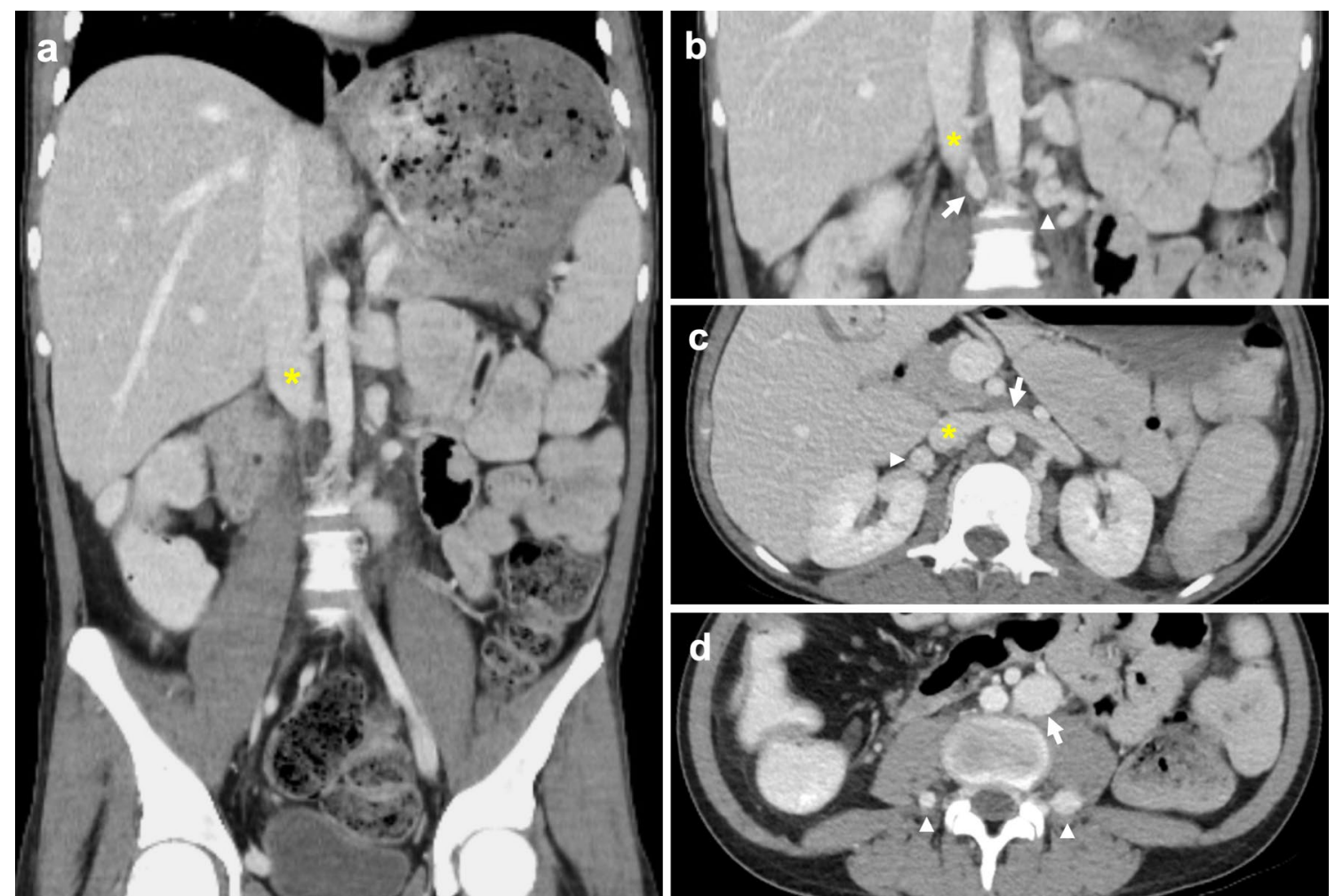

Fig. 7 Absent infrarenal IVC with azygos continuation. Paired common iliac veins continue cranially as bilateral ascending lumbar veins. a Contrast-enhanced coronal CT demonstrates the caudal end of the IVC (asterisk). b Coronal CT shows the right ascending lumbar vein (arrow) approaching and subsequently draining into the IVC (asterisk). Tortuous paravertebral collateral veins (arrowhead) are present adjacent to the aorta. c Axial CT image with left renal vein (arrow) crossing anterior to the aorta to drain into the renal IVC segment (asterisk). Right renal vein (arrowhead) also approaches renal IVC segment. d Axial CT shows prominent bilateral ascending lumbar veins (arrowheads) and a distended paravertebral collateral (arrow) positioned left of the aorta

$[16,27]$. Lastly, if this anomaly is not recognised, recurrent pulmonary embolism can occur despite routine infrarenal IVC filter placement $[28,29]$. Solutions for this scenario include bilateral infrarenal IVC filter placement, suprarenal IVC filter placement, and steel coil embolisation [30-32].

\section{Left-sided IVC}

Abnormal regression of the right supracardinal vein and persistence of the left supracardinal vein results in a leftsided IVC, with a prevalence of $0.2-0.5 \%$ [18]. Bilateral common iliac veins drain into the left-sided IVC which typically course superiorly to join the left renal vein (Fig. 6). Known variants to this configuration include hemiazygos continuation of the left-sided IVC, and an associated retroaortic right renal vein [12, 22, 33]. Identifying a left-sided IVC is important as it can complicate procedures such an abdominal aortic aneurysm repair, left-sided nephrectomy, oblique lumbar fusion or IVC filter placement $[7,34-37]$.

\section{Absent infrarenal IVC}

An absent infrarenal IVC, also known as interruption of the infrarenal IVC or infrarenal agenesis of IVC with azygos continuation, is postulated to be caused by acquired intrauterine or perinatal venous thrombosis, rather than failure of embryonic vein development $[7,38,39]$. This leads to failure of posterior cardinal and supracardinal vein development, resulting in external and internal iliac veins draining into the azygos-hemiazygos system via ascending lumbar veins, and a preserved suprarenal IVC segment (Fig. 7) [39, 40]. It is a rarely described anomaly with unknown incidence [11, 39, 41, 42]. Affected patients are at risk of developing lower extremity venous insufficiency, deep vein thrombosis, varicose veins and pelvic congestion syndrome [10-15]. In the absence of adequate flow through ascending lumbar veins and the azygos system, other collateral pathways can form involving abdominal wall, pelvic, gonadal and retroperitoneal vessels (Fig. 8) [13]. 

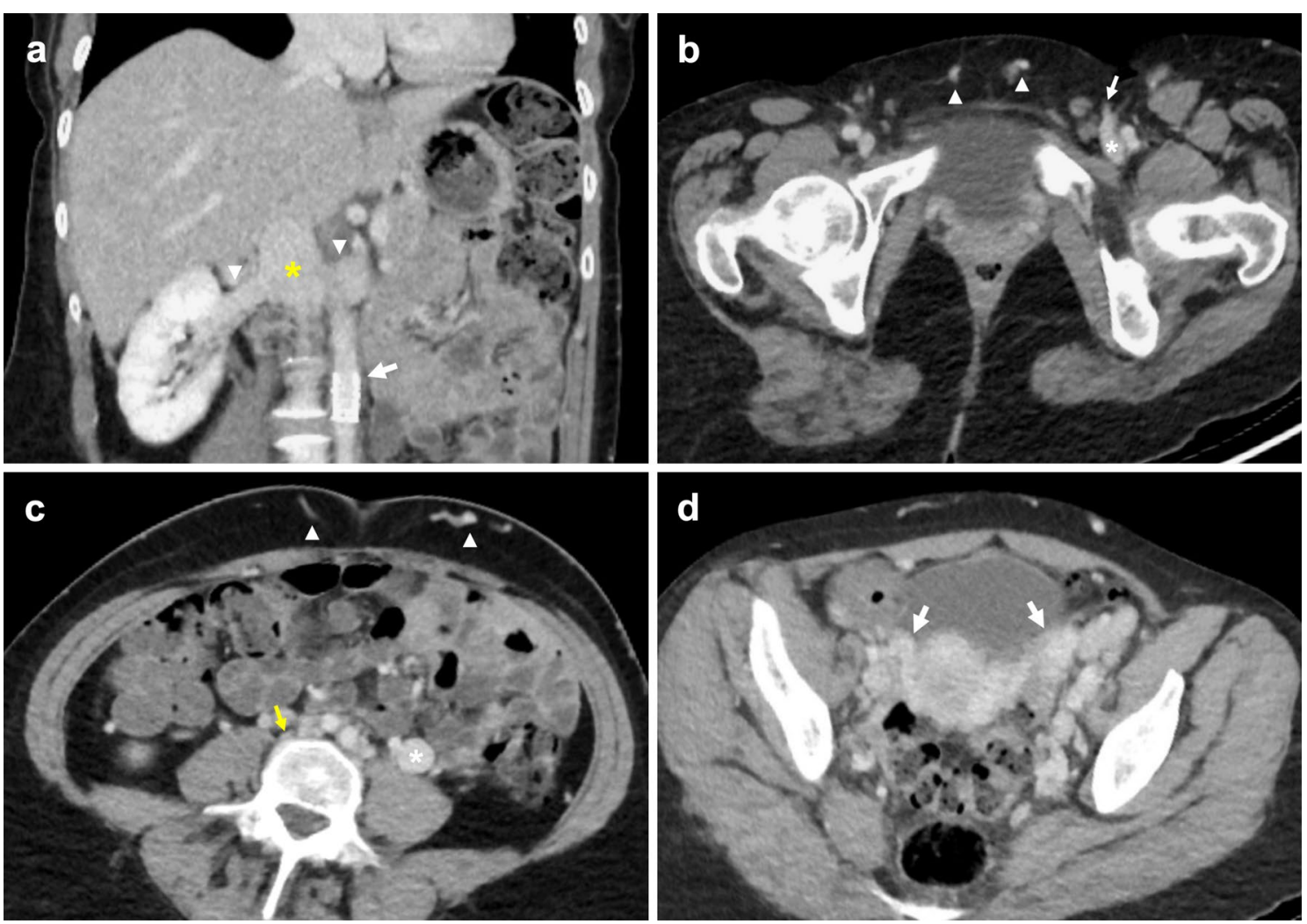

Fig. 8 Absent infrarenal IVC with multiple collateral pathways. Contrast-enhanced delayed venous phase on a CT abdomen and pelvis demonstrates prominent superficial abdominal, epigastric and gonadal veins draining the lower extremities. a Coronal CT image shows paired renal veins (arrowheads) draining into the caudal end of the IVC (asterisk). An aortic stent (arrow) is visualised inferior to the left renal vein. b Axial CT shows prominent external pudendal veins (arrowheads), and the left femoral vein (asterisk) receiving a distended superficial inferior epigastric vein (arrow). c Axial CT image with a distended left gonadal vein (asterisk). Small calibre unenhanced infrarenal IVC (arrow) is suggestive of chronic occlusion. Enhanced right inferior epigastric and abdominal wall veins are also visualised (arrowhead). $\mathbf{d}$ Axial CT demonstrates bilateral enlarged pelvic veins (arrows)

\section{Interrupted IVC with azygos continuation}

Interrupted IVC with azygos continuation classically refers to interruption of the suprarenal/infrahepatic segment and occurs due to failure of the right subcardinal vein to anastomose with the vitelline vein $[7,43]$. An interrupted IVC has been described in various ways with 'interrupted' being interchanged for absence, anomalous or agenesis [13, 22, 44]. The suprarenal IVC reroutes to drain via the azygos vein, while the hepatic IVC only receives the hepatic veins. It carries a prevalence of $0.6 \%$ and is classically associated with polysplenia, cardiovascular malformations and situs anomalies $[7,16,45]$. Like an absent infrarenal IVC, an interrupted IVC without adequate collateral pathways can similarly result in vascular problems such as deep vein thrombosis and venous insufficiency. An enlarged azygos vein can be misinterpreted as retrocrural lymphadenopathy or a right paratracheal mass, while a distended hemiazygos vein may simulate a left-sided mediastinal mass $[43,46$,
47]. Prominent collateral vessels can also be mistaken for paraspinal masses (Fig. 9) [42]. Preoperative awareness of this anomaly is important prior to thoracic and cardiopulmonary bypass surgery $[48,49]$.

Koc et al. uses a straightforward nomenclature that identifies all anomalies with absent or interrupted segments as 'interrupted IVC', followed by the level of interruption and associated collaterals, i.e. 'interrupted IVC (suprarenal level) with azygos continuation' [12]. In this review, we report a rarely described case of interrupted IVC of the renal segment with azygos continuation (Fig. 10) [13]. Instead of draining directly into the IVC, the left renal vein drains into a tortuous paravertebral collateral that eventually joins the hemiazygos vein, while the right renal vein continues to drain directly into the IVC. Paired common iliac veins continue as bilateral ascending lumbar veins to join a distended azygos-hemiazygos system. Lastly, acquired pathology such as complete stenosis of the suprarenal IVC results in anatomy 

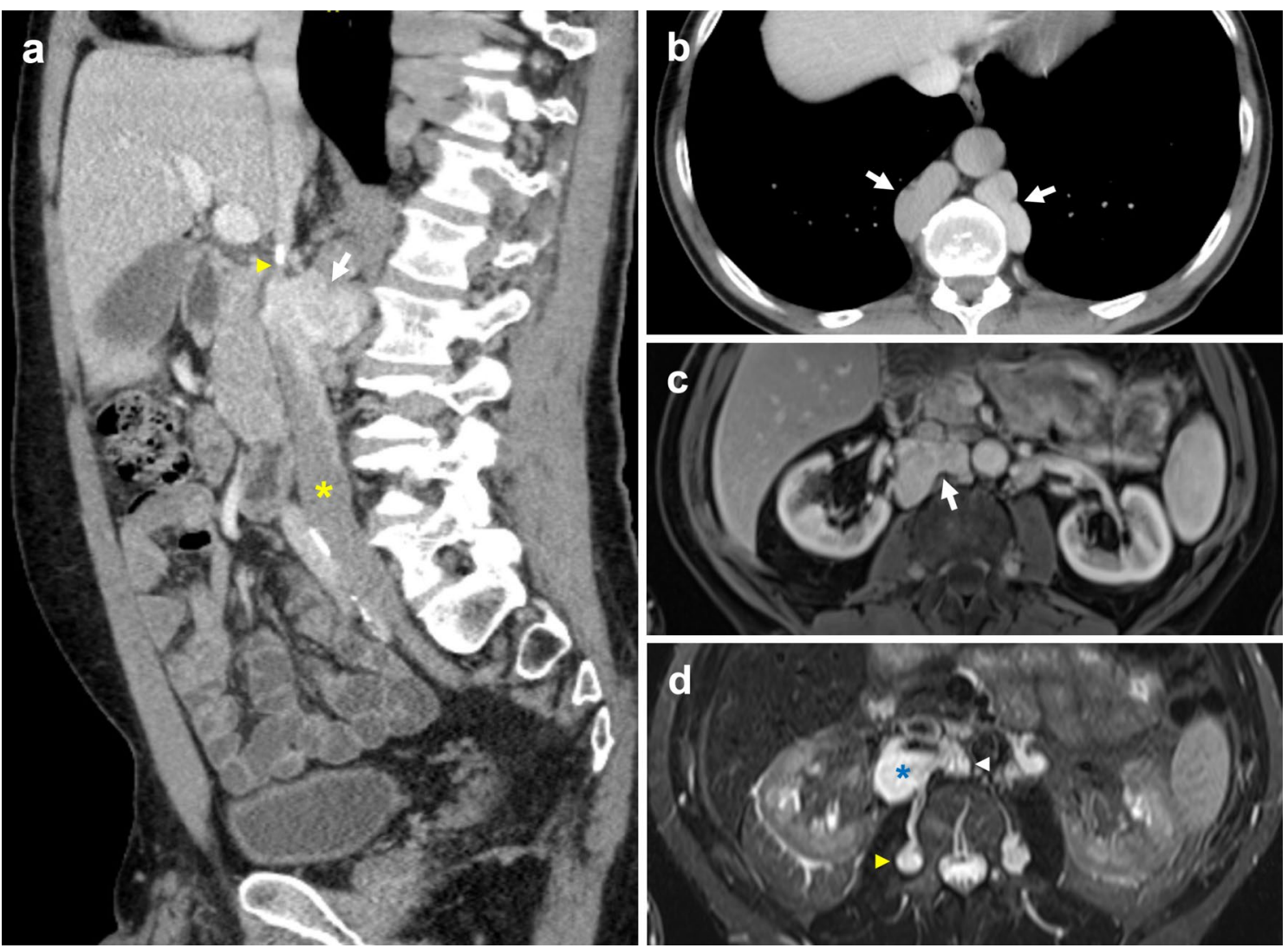

Fig. 9 Distended collateral vein mistaken for mass in context of incidentally detected suprarenal IVC stenosis. The 54-year-old man had no previous history of IVC filter insertion or intrabdominal surgery. a Contrast-enhanced sagittal CT shows a pseudomass (arrow) immediately posteroinferior to complete stenosis (arrowhead) of the suprarenal IVC, with caudal segments of the IVC (asterisk) preserved. A small focus of calcification is present at the level of the stenosis. b Axial CT shows preferential blood flow through markedly distended azygos and hemiazygos veins (arrows). c Axial MRT1 VIBE image shows a well-defined lobulated mass (arrow) with venous enhancement. $\mathbf{d}$ Axial MRT2 image of the mass (asterisk) shows high T2 signal in keeping with slow venous flow. It communicates posteriorly with the right ascending lumbar vein (yellow arrowhead) and medially with a right paravertebral collateral vein (white arrowhead)

similar to a congenital interrupted IVC, with development of collateral pathways and preferential blood flow into the paravertebral, azygos and hemiazygos systems (Fig. 9).

\section{Acquired pathologies}

Acquired conditions affecting the IVC include primary and secondary malignancy with or without intravascular extension, benign tumours, extrinsic compression, bland thrombus, and chronic obstruction. Primary IVC malignancy is rare, representing less than $1 \%$ of all malignancies [50,51]. In contrast, secondary IVC malignancy is much more common and often results from tumour thrombus, i.e. direct intravascular extension from an abdominal primary such as kidney, liver or adrenal gland [16]. Metastatic lesions may also invade the caval wall, the most common of which are liver metastases from colorectal cancer [52, 53]. Lung carcinoma involving the IVC is extremely rare, and in this review, we present a case of adrenal metastases from non-small cell lung carcinoma (NSCLC) with extension into the suprarenal IVC (Fig. 11) [54]. Tumours such as pheochromocytoma and leiomyomas are typically benign; however, there are reports of IVC invasion and metastasis [55, 56]. The IVC may also be compressed extrinsically by tumours such as lymphoma, causing symptoms of IVC syndrome such as lower limb and lower torso swelling (Fig. 12). Furthermore, distinguishing tumour from bland thrombus is important to guide anticoagulation therapy [57]. Enhancement of the filling defect, expansion of the vessel lumen, contiguity with mass and increased FDG uptake on PET-CT are findings characteristic of tumour thrombus $[58,59]$. Compared to CT, MRI demonstrates superior characterisation of thrombus composition, identifying a greater proportion of tumour thrombi 


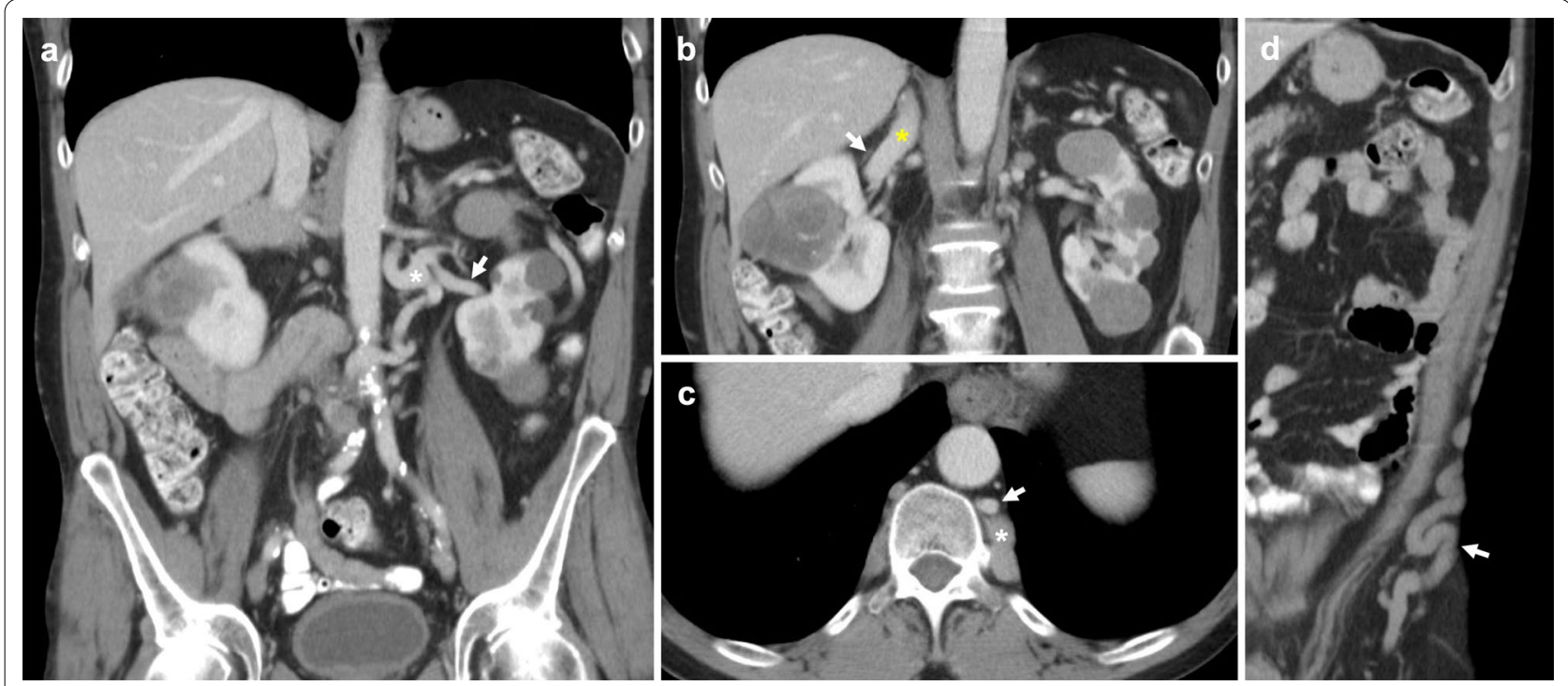

Fig. 10 Interrupted IVC (renal level) with azygos and hemiazygos continuation. Anomaly detected incidentally on imaging for a 55-year-old man with biopsy proven renal cell carcinoma. The paired common iliac veins continue as bilateral ascending lumbar veins draining into the azygoshemiazygos system. a Contrast-enhanced coronal CT shows the left renal vein (arrow) draining into a tortuous paravertebral collateral (asterisk). $\mathbf{b}$ The right renal vein (arrow) joins the suprarenal IVC (asterisk). c Axial CT image depicts a left-sided paravertebral collateral (arrow) that drains into the hemiazygos vein (asterisk) sited posteriorly. $\mathbf{d}$ Coronal CT image with a prominent lateral abdominal wall collateral vein
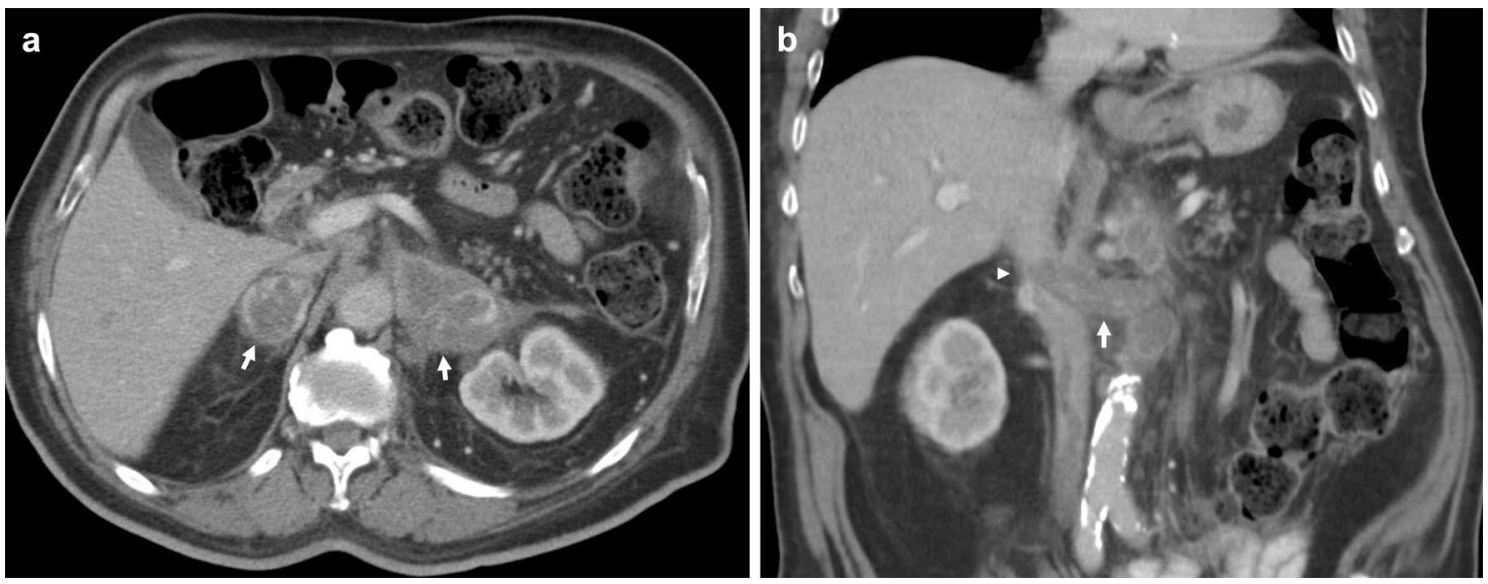

Fig. 11 Adrenal metastases with suprarenal IVC tumour thrombus in a patient with small cell lung carcinoma primary. a Axial CT shows bilateral suprarenal lesions with heterogeneous peripheral enhancement in keeping with bilateral adrenal metastases. $\mathbf{b}$ Coronal CT demonstrates extension of tumour into the left renal vein (arrow) and suprarenal IVC (arrowhead). The heterogeneous appearance of the suprarenal IVC is due to a combination of tumour thrombus and flow artefact

[60]. Finally, determining the extent of IVC involvement affects staging and is critical to surgical planning.

\section{Primary malignancy \\ IVC Leiomyosarcoma}

IVC leiomyosarcoma is the most common primary malignancy of the IVC and the most common type of retroperitoneal leiomyosarcoma [61]. It is a rare slow-growing smooth muscle cell malignancy that usually occurs in middle-aged women [50, 62-64]. Whilst initial growth is intramural, two-thirds of tumours will eventually demonstrate extraluminal growth [63-65]. Intraluminal tumours can cause venous obstruction, whilst extraluminal tumours can be confused with secondary malignancy from surrounding organs (Fig. 13) [66].

Whilst amenable to wide local excision, it carries a poor prognosis with studies showing $94 \%$ recurrence at 5 years and $14 \%$ survival at 10 years $[62-64,67]$. The level of IVC 


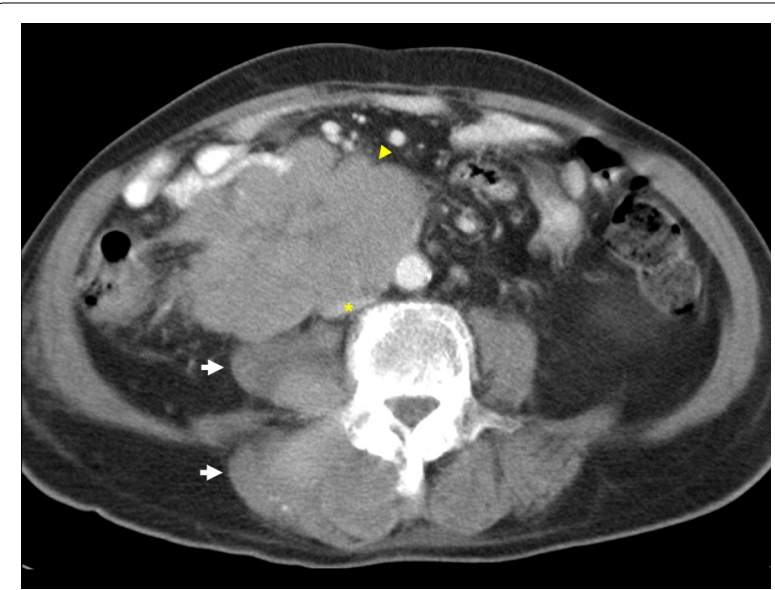

Fig. 12 Extrinsic compression of IVC. Contrast-enhanced axial image demonstrating extrinsic compression of the IVC (asterisk), which is flattened, secondary to a large nodal mass (arrowhead) from lymphoma. Further lymphomatous infiltration of the right psoas and paravertebral muscles is also present (arrows) involvement is an important prognostic factor and can be divided by infrarenal (34-44\%), suprarenal (42-50\%) and suprahepatic (6-24\%) involvement, with $21-36 \%$ of cases involving two or more segments $[63,68,69]$. Renal and suprarenal IVC leiomyosarcomas (42-50\%) carry the most favourable prognosis, whilst suprahepatic tumours have the worst outcomes due to poor surgical resectability $[62,65]$.

A key characteristic of this tumour is a retroperitoneal mass limited to the IVC. Nishino et al. describe the positive embedded organ sign which is useful for identifying masses that arise from plastic organs such as a vein (Fig. 14) [70]. In this case, IVC leiomyosarcoma will appear embedded in the vessel wall. An imperceptible caval lumen is another specific sign for IVC leiomyosarcoma, in which signal from the IVC is imperceptible at the point of contact between the tumour and the IVC [71]. On both CT and MRI, the mass can demonstrate heterogeneous enhancement due to central cystic or necrotic components (Fig. 13) [72, 73].
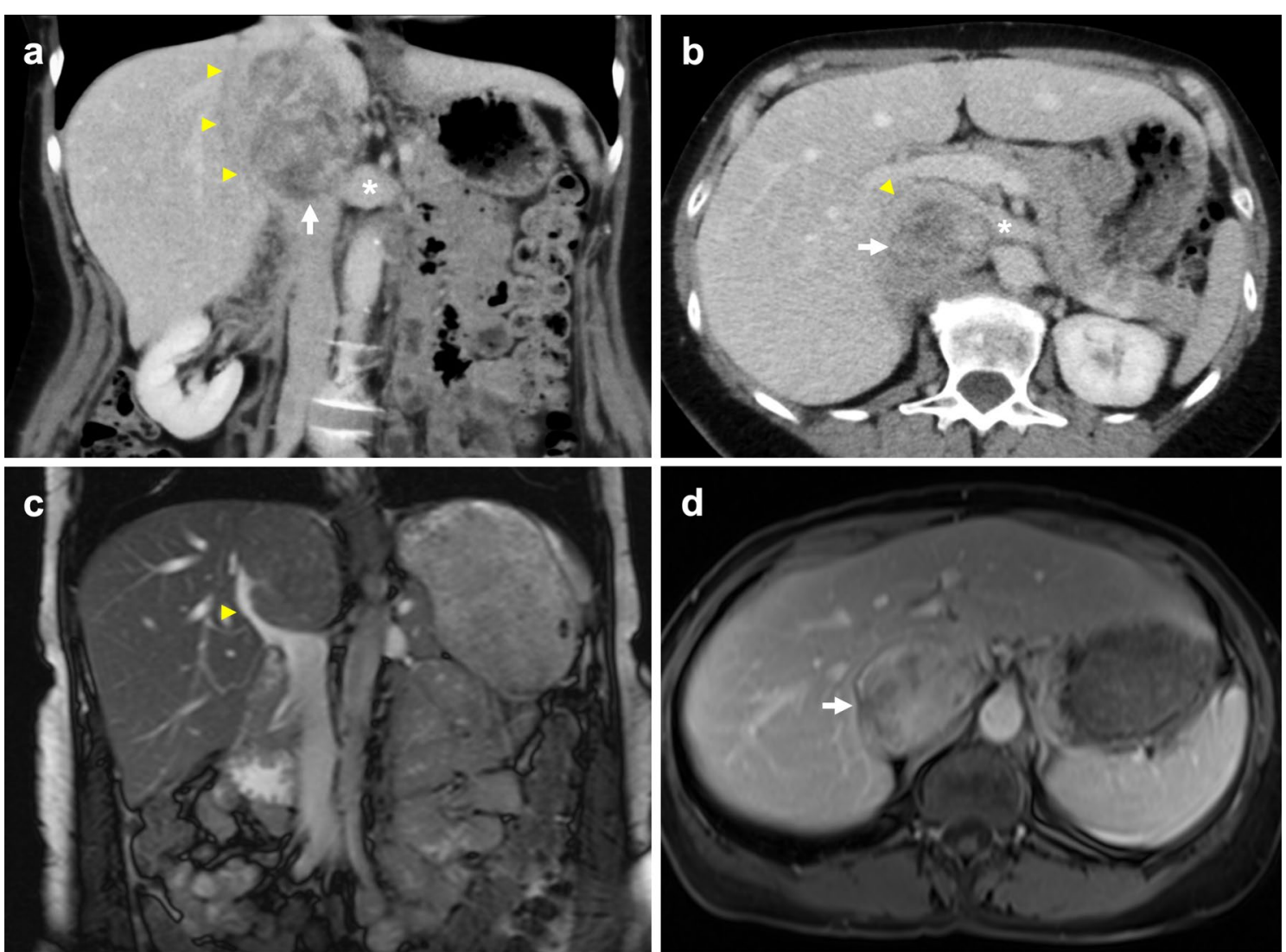

Fig. 13 IVC Leiomyosarcoma mistaken for adrenal lesion. a,b Coronal and axial contrast-enhanced CT demonstrate a heterogeneous mass (white arrows) displacing the left renal vein (asterisks) anteriorly and hepatic cava (yellow arrowheads) anterolaterally to the right. c T2-weighted axial MR image shows the effacement of the hepatic cava (arrowhead) without invasion of adjacent structures. $\mathbf{d}$ Contrast-enhanced T1-weighted fat-saturated axial image demonstrates heterogeneous enhancement of the tumour (arrow) 


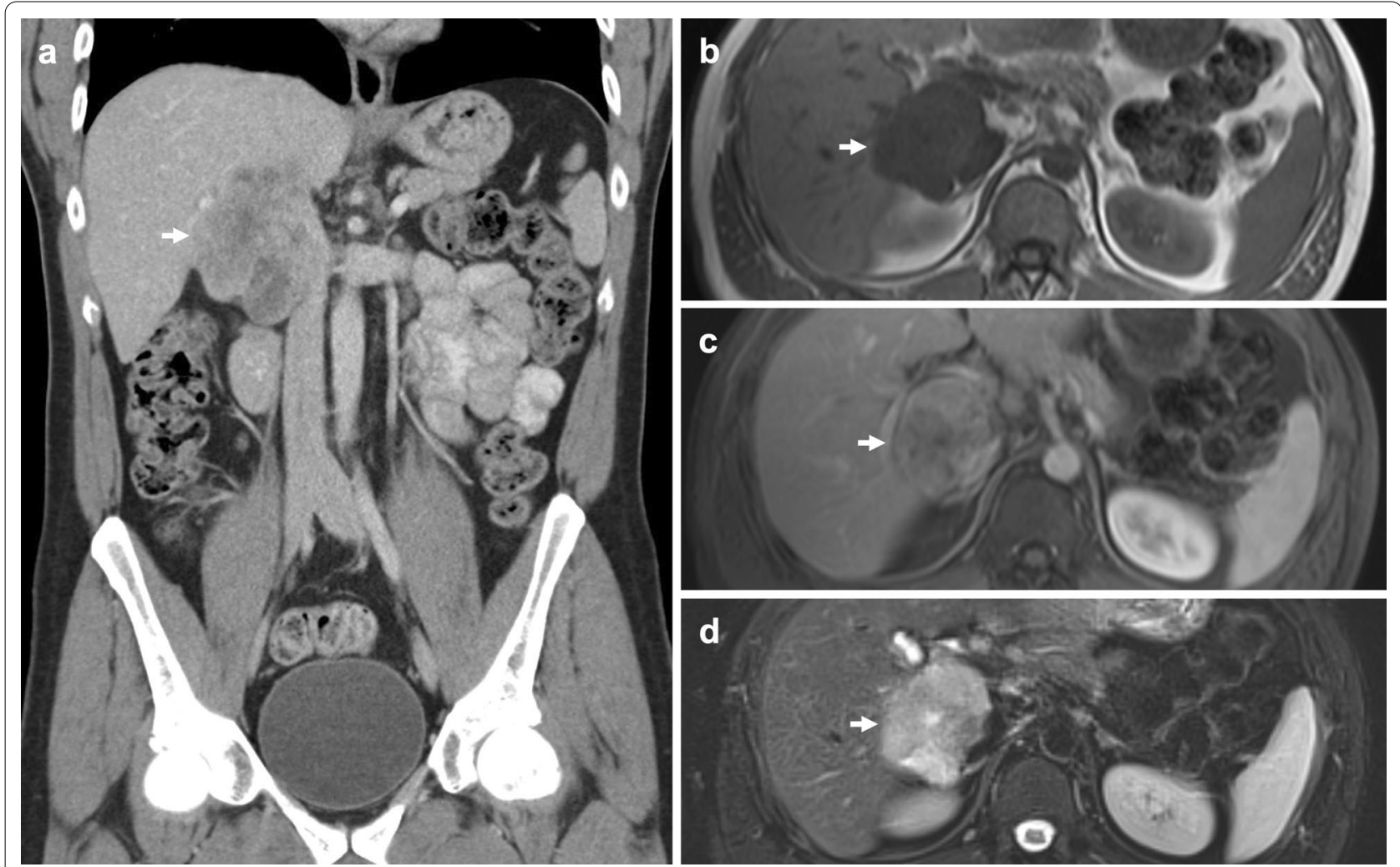

Fig. 14 IVC Leiomyosarcoma. a Coronal CT image shows a large lobulated heterogeneously enhancing mass (arrow) between the liver and right kidney. It demonstrates both intra and extraluminal growth. On axial MRI, the lesion (arrows) is (b) homogeneously T1 hypointense to skeletal muscle, (c) enhances heterogeneously, and (d) is heterogeneously T2 hyperintense. Some non-enhancing areas are bright on T2 weighted sequences, suggestive of cystic or necrotic components. MRI also demonstrates a positive embedded organ sign

\section{Secondary malignancy}

\section{Renal cell carcinoma}

Renal cell carcinoma (RCC) is the most common secondary malignancy of the IVC, with $4-10 \%$ of cases demonstrating intravascular spread; an independent prognostic factor for decreased survival rates [74, 75]. RCC tumour thrombus shows little tendency to invade vessel walls; however, when it occurs, it also worsens prognosis [76, 77]. Despite this, complete resection of non-metastatic RCC with IVC extension carries a reasonable 5 -year survival rate of $37-68 \%[78,79]$.

Although some practices continue to use the Robson staging system for RCC, it has largely been replaced by the tumour-node-metastasis (TNM) classification system of malignant tumours. Stages T3a, T3b and T3c correspond to renal vein, infradiaphragmatic and supradiaphragmatic IVC extension, respectively, with invasion of the IVC wall also considered to be stage T3c [80]. Increasing venous tumour thrombus extension is negatively associated with long-term survival and alters surgical management $[79,81,82]$. A multi-institutional study of 1122 patients showed a 5 -year survival of $22 \%$ for stage T3c disease compared to $43.2 \%$ for T3a disease [79].

The most frequently used classification for RCC tumour thrombus is the Mayo system introduced by Neves and Zincke which stratifies IVC thrombus into 4 levels; level I extending $<2 \mathrm{~cm}$ from the renal ostia, level II extending $>2 \mathrm{~cm}$ but below the intrahepatic vena cava (Fig. 15), level III involving the intrahepatic IVC (Fig. 16), and level IV being supradiaphragmatic [83]. Mayo level I tumours are generally easy to milk into the renal vein, level II tumours require more extensive vena cava dissection, and level III/IV tumours are associated with higher early complications and often require veno-venous or cardiopulmonary bypass [84].

Both CT and MRI show high accuracy for detecting tumour thrombus, assessing its extent and distinguishing it from bland thrombus (Fig. 15) [85-87]. CT demonstrates $96 \%$ accuracy in the corticomedullary phase and allows for simultaneous imaging for metastatic disease $[86,88]$. Whilst there has not been a systematic comparison between CT and MRI for detecting IVC wall involvement, both modalities have been shown to 


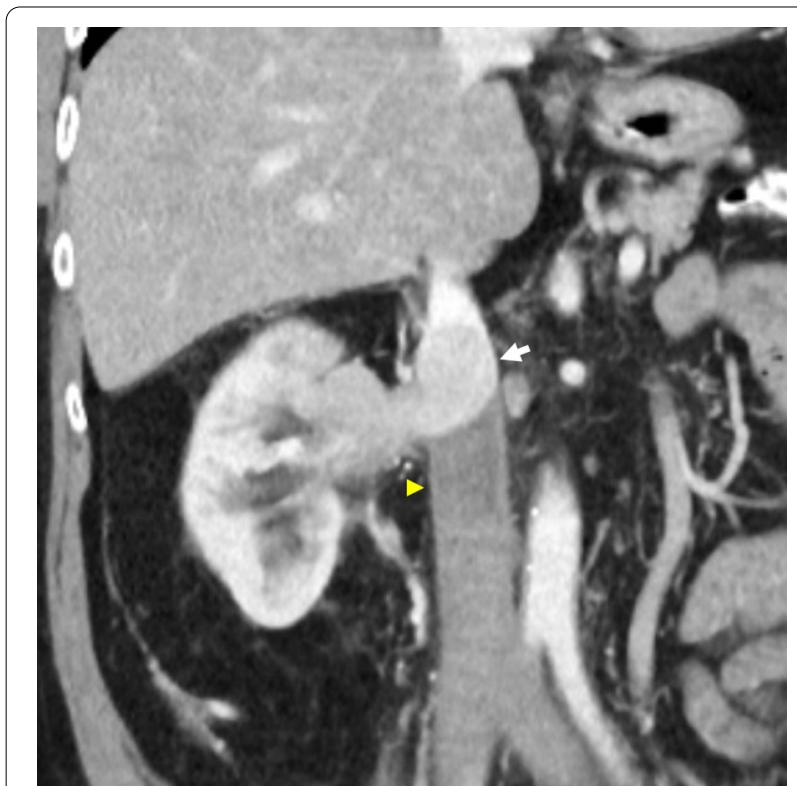

Fig. 15 Renal cell carcinoma with Mayo level Il tumour thrombus and infrarenal bland thrombus. Coronal CT demonstrates occlusive enhancing tumour thrombus (arrow) extending from the right renal vein into the suprarenal IVC. Infrarenal IVC (arrowhead) and iliac vessels show no contrast enhancement and are expanded in keeping with bland thrombus reliably predict wall invasion which requires more complicated surgery involving IVC resection. Adams et al. showed complete venous occlusion or vessel breach (tumour signal on both sides of the vessel wall) on MRI can reliably predict intraoperative wall adherence [89]. Moreover, Psutka et al. demonstrated imaging features such as a right-sided RCC, complete IVC occlusion at the right renal vein ostium and anteroposterior IVC diameter $\geq 24 \mathrm{~mm}$ at that same level were associated with an increased chance of IVC resection [87]. Lastly, IVC wall invasion can be confidently excluded if tumour thrombus does not contact the vessel wall [89].

Patients with adherent tumour thrombus invading the IVC wall require en bloc excision, including segmental resection and reconstruction of the vessel, and tumour thrombectomy. Whilst the majority of radical nephrectomies with venous thrombectomy are performed by open surgery, there is an increasing trend towards minimally invasive laparoscopic and robotic approaches [81].

\section{Hepatocellular carcinoma}

Hepatocellular carcinoma (HCC) typically invades the portal venous system; however, involvement of the IVC is not uncommon, occurring in $4.0-5.9 \%$ of patients either through extension of hepatic vein tumour thrombus or direct wall invasion $[61,90]$. Tumour thrombus
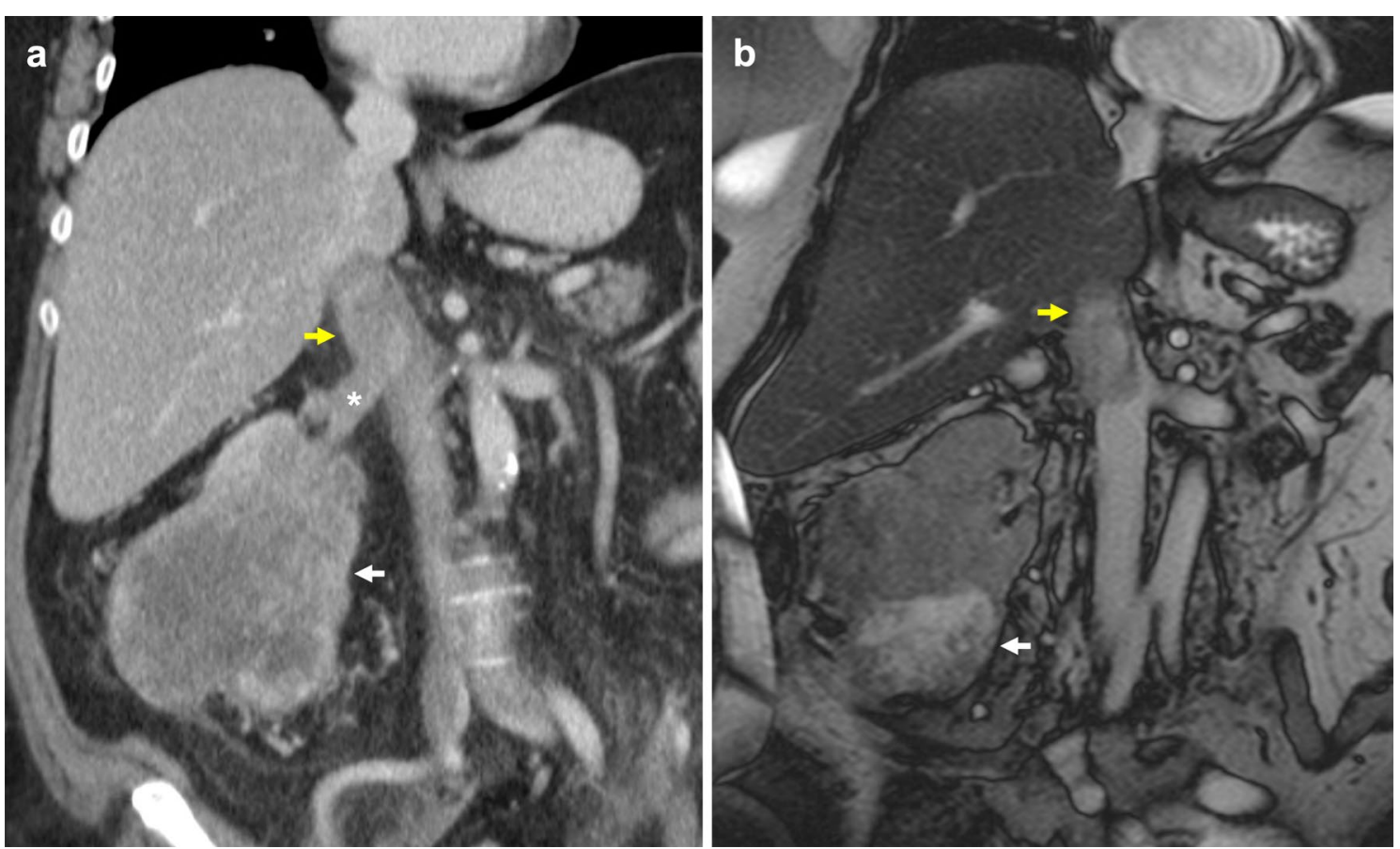

Fig. 16 Renal cell carcinoma with Mayo level III thrombus. a Coronal CT shows a large heterogeneous renal mass (white arrow), expanded right renal vein (asterisk) and heterogeneous enhancement extending into the suprarenal IVC (yellow arrow) in keeping with tumour thrombus (b) T2-weighted coronal image confirms extension of tumour thrombus into the suprarenal and intrahepatic IVC (yellow arrow), which returns similar heterogeneous T2 signal as the primary renal cell carcinoma (white arrow) 

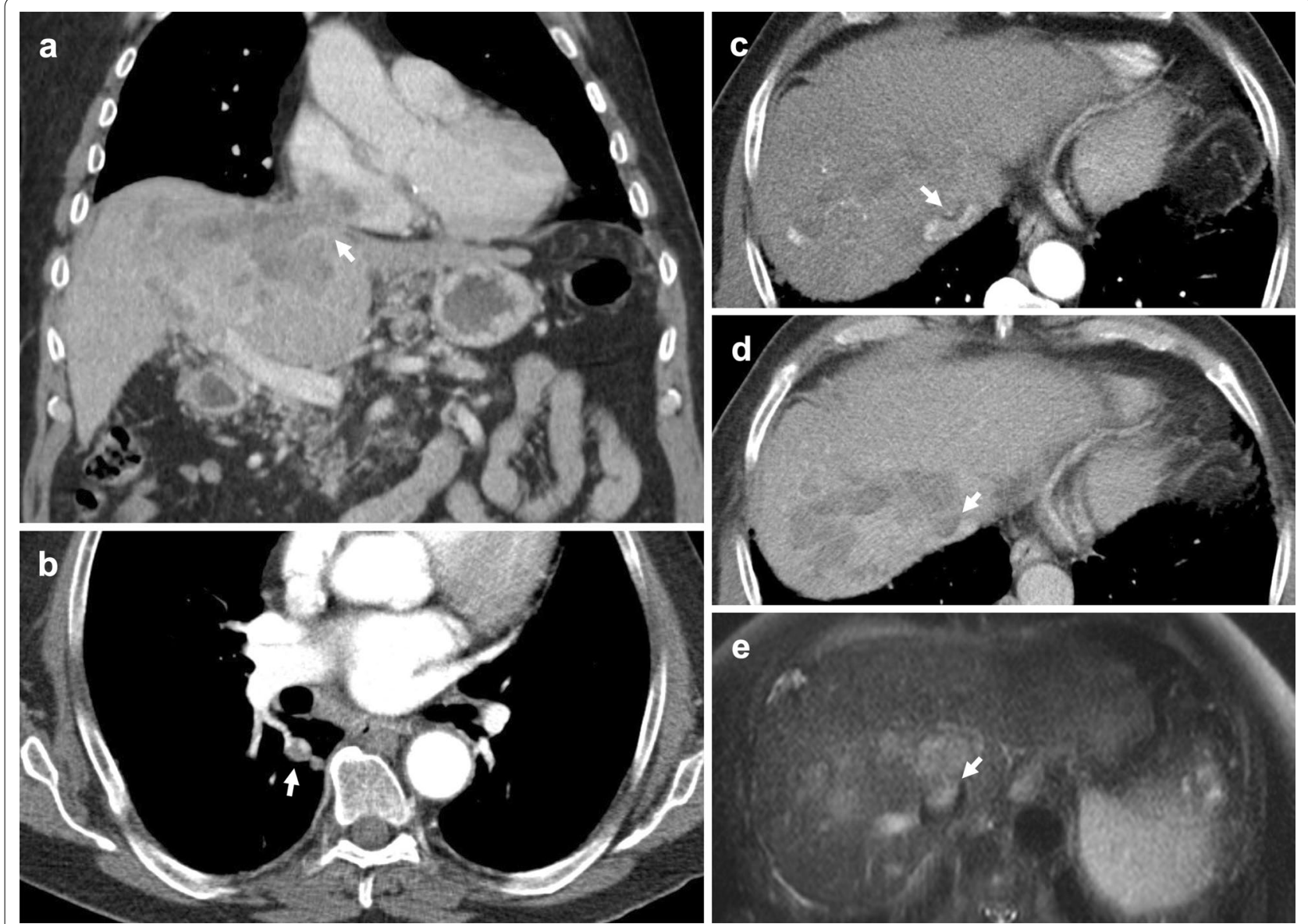

Fig. 17 Hepatocellular carcinoma with IVC tumour thrombus, direct invasion of the right atrium and embolic tumour thrombus. a Contrast-enhanced coronal CT depicts direct invasion of the HCC (arrow) into the right atrium. b Axial CT chest shows subsegmental right pulmonary artery dilatation with internal filling defect (arrow), likely due to embolic tumour thrombus. c Axial CT shows multifocal arterial enhancement in the liver, predominantly in segment 7 and 8 . The IVC tumour thrombus also demonstrates arterial enhancement (arrow), $\mathbf{d}$ is visualised as a partial filling defect (arrow) in portal venous phase, and $\mathbf{e}$ shows intermediate T2 signal (arrow) with extension into the hepatic IVC via the middle hepatic vein

is uncommon in other hepatic malignancies and therefore, should be considered a differentiating feature of HCC [91]. IVC and right atrial involvement carries an extremely poor prognosis due to predisposition to metastatic disease, carrying a median survival of 1-5 months [92-94]. Hepatic venous outflow obstruction may cause Budd-Chiari syndrome and clinical manifestations of portal hypertension [95]. Tumour thrombus may also embolise and obstruct pulmonary arteries (Fig. 17) [96].

Most studies focus on imaging findings of portal vein tumour thrombus; however, parallels may be drawn when identifying IVC tumour thrombus. On CT, HCC tumour thrombus demonstrates hepatic vein expansion and arterial enhancement with washout in the portal vein and delayed phases (Fig. 18). Catalano et al. have shown that diffusion-weighted imaging may be employed to differentiate bland thrombus from tumour extension, with bland thrombus eliciting higher ADC values [97]. Patients typically have concomitant liver dysfunction, poor prognosis and high rate of recurrence; therefore, HCC with IVC invasion is considered an absolute contraindication to liver transplantation and managed non-surgically. However, recent studies have shown that sorafenib, external beam radiotherapy and surgery with careful patient selection can improve clinical outcomes $[98,99]$.

\section{Adrenal cortical carcinoma}

Adrenal cortical carcinoma (ACC), also known as adrenocortical carcinoma, is a rare and aggressive malignancy with an incidence of approximately 1 to 2 in a million, and bimodal age distribution with peaks at under 5 years 

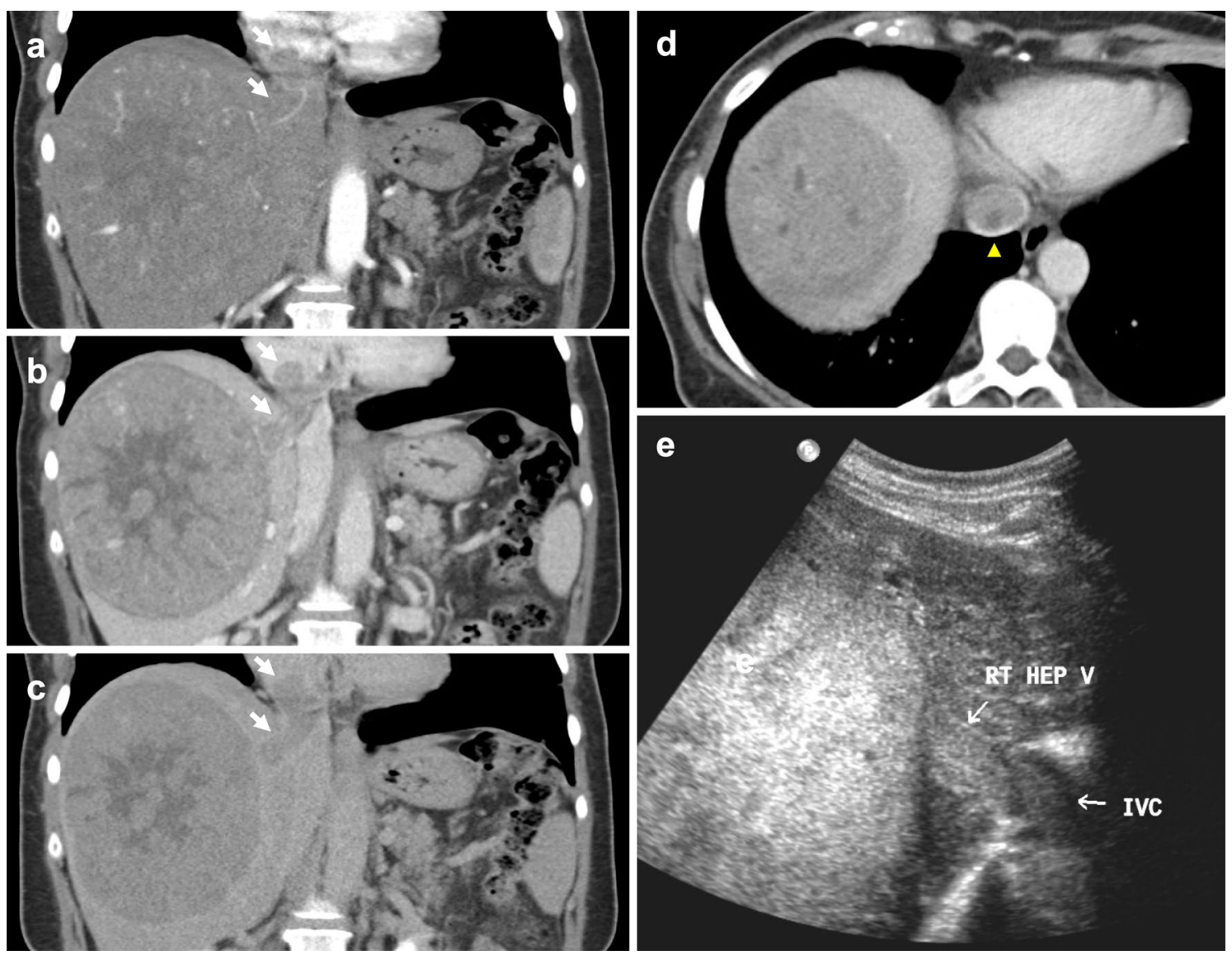

Fig. 18 Hepatocellular carcinoma invading the IVC. a-c Coronal multiphase CT images show a $12 \times 11 \mathrm{~cm}$ necrotic hepatic lesion invading the hepatic and supradiaphragmatic IVC. The thrombus (arrows) demonstrates enhancement in both (a) arterial and (b) portal venous phases, with complete washout in the (c) delayed phase. $\mathbf{d}$ Axial CT shows near complete obstruction of the hepatic IVC (arrowhead). e US Abdomen demonstrates a hyperechoic hepatic mass extending into the right hepatic vein and IVC

of age and the 4th to 6th decades of life [100, 101]. Rate of local recurrence is high, and half of adult patients present with advanced disease [101]. $62 \%$ of cases are reported to be endocrinologically functional, manifesting as Cushing's syndrome, Conn's syndrome, feminisation or virilisation secondary to elevated androgens [101]. Most ACC tumours are larger than $6 \mathrm{~cm}$, have irregular margins and enhance heterogeneously on both CT and MRI due to central areas of necrosis and haemorrhage (Fig. 19) [102, 103]. The presence of $\mathrm{T} 1$ hypointensity, $\mathrm{T} 2$ hyperintensity and heterogeneous signal drop on chemical shift imaging further supports diagnosis of ACC [103-105]. Moreover, they demonstrate contrast retention on delayed contrastenhanced $\mathrm{CT}$, with a relative percentage washout of less than $40 \%$ [106]. Invasion into the IVC is classified as Stage III disease and occurs in $9-19 \%$ of cases $[101,107]$. One study found tumour thrombus was more common in right-sided ACC and tumours larger than $9 \mathrm{~cm}$ [86].

\section{Pheochromocytoma}

Pheochromocytoma is a rare tumour that typically originates from chromaffin cells of the adrenal medulla. $15-20 \%$ of these are extra-adrenal, arising from paraganglion chromaffin tissue of the nervous system and are also known as paragangliomas [108]. Known associations include familial syndromes such as von Hippel-Lindau disease, MEN 2A and 2B and neurofibromatosis type 1 [109]. Patients may present with back pain and symptoms consistent with catecholamine secretion [110]. Although pheochromocytomas are usually benign, $32-52 \%$ of all extra-adrenal pheochromocytomas are malignant with an increased propensity to metastasise and invade local structures such as the caval wall (Fig. 20) [111-113]. These tumours typically enhance heterogeneously with delayed washout on both CT and MRI and may show marked T2 hyperintensity $[114,115]$. When ruling out 


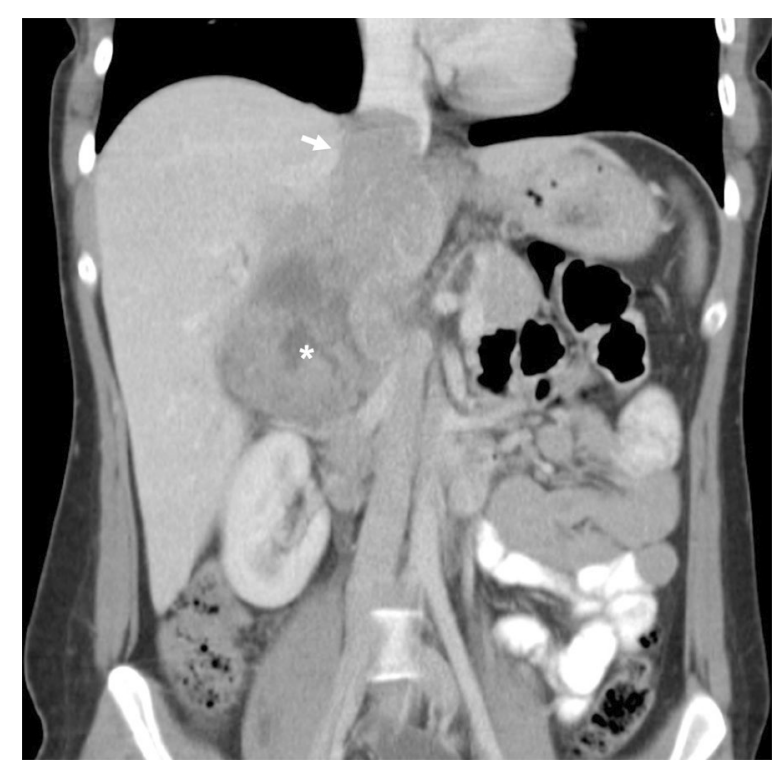

Fig. 19 Adrenal cortical carcinoma invading IVC. Portal venous CT coronal image demonstrates a large adrenal cortical carcinoma (asterisk) with irregular margins, areas of necrosis and invasion of the IVC (arrow) metastases, CT in combination with functional imaging such as ${ }^{18} \mathrm{~F}$-FDA or ${ }^{123} \mathrm{I}-\mathrm{MIBG}$ may be employed [116]. Surgical resection is the treatment of choice with pre-operative blood pressure control required to prevent intraoperative hypertensive crises [117].

\section{Thrombosis}

IVC thrombosis carries significant morbidity and mortality, with a high risk for pulmonary embolism [118]. Commonly reported causes include anomalous venous anatomy, extraluminal or intraluminal obstruction by malignancy, extension of deep vein thrombosis (DVT) and unretrieved IVC filters [119]. 5-16\% of young patients presenting with iliofemoral DVT had IVC anomalies, with most cases attributed to IVC interruption/agenesis likely secondary to venous stasis from poor collaterals (Fig. 21) [120-123]. Up to $4 \%$ of patients with lower limb DVT experience IVC thrombosis (Fig. 22a) [119]. Common predisposing factors such as malignancy, localised inflammation and coagulopathy cause hypercoagulable states (Fig. 22b). In addition to malignancyrelated hypercoagulability, tumour invasion by renal cell
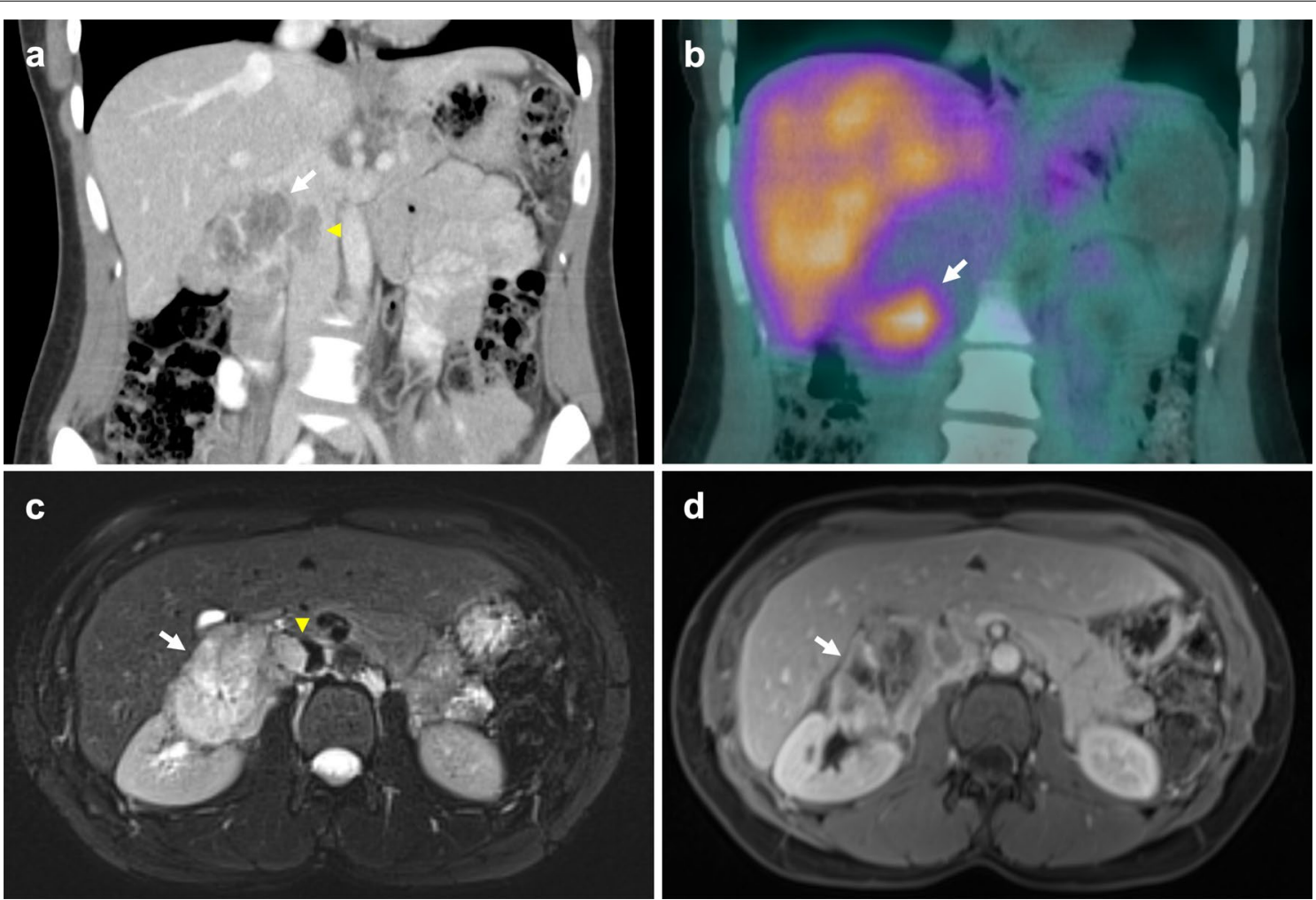

Fig. 20 Malignant extra-adrenal phaeochromocytoma invading IVC. a Coronal portal venous phase CT shows a heterogeneously enhancing peri-renal mass (arrow) with possible central necrosis that abuts and extends into the infrarenal IVC (arrowhead). b SPECT CT demonstrates a focus of abnormal MIBG uptake (arrow) within the region of the peri-renal mass. Selected MR images show the retroperitoneal lesion (c) partially obstructing the IVC (arrowhead), demonstrating heterogeneous elevated T2 signal (arrow) on the selected T2-weighted fat-saturated axial image and (d) heterogeneous enhancement (arrow) on the selected T1-weighted fat-saturated axial image 

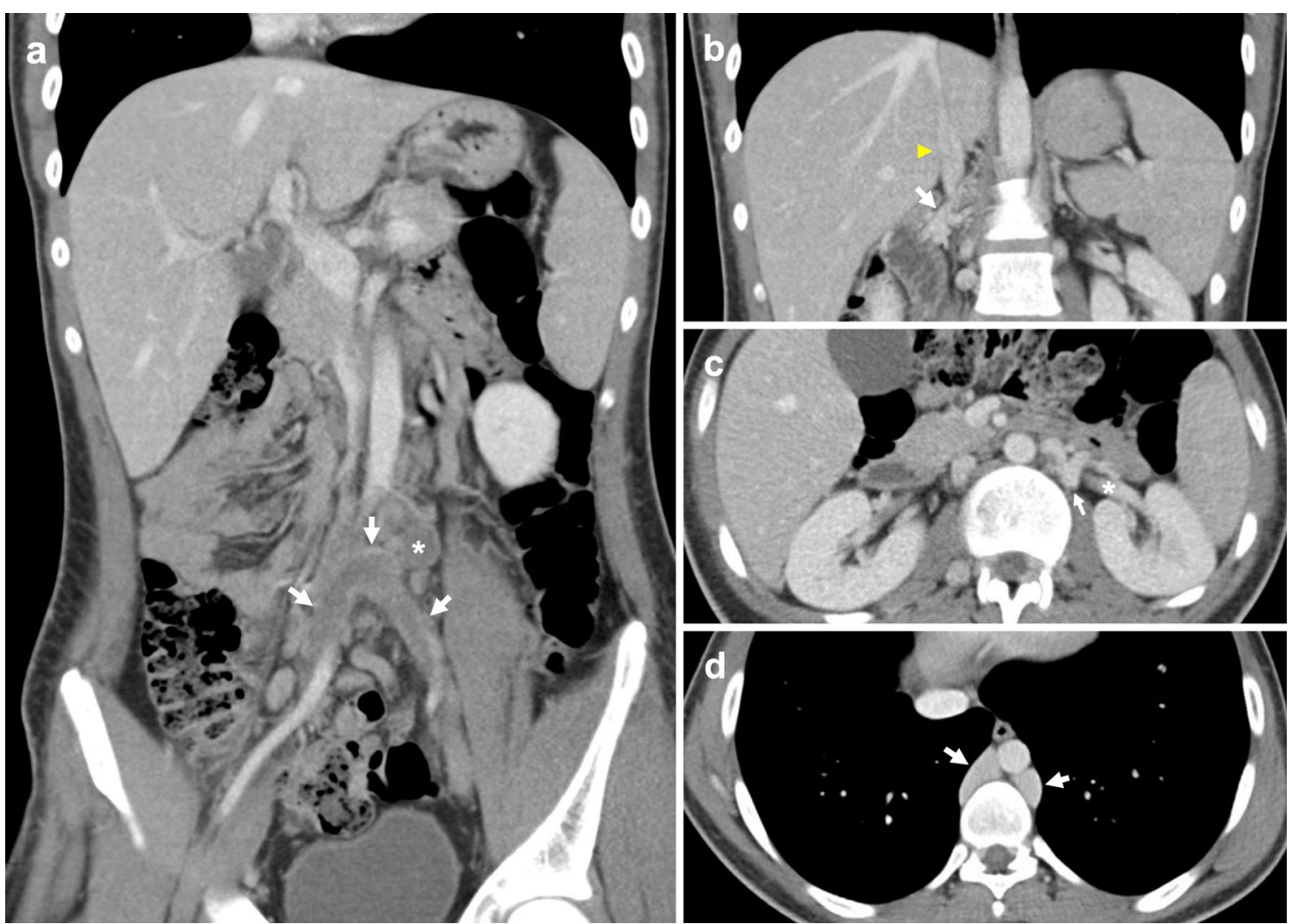

Fig. 21 Extensive venous thrombus secondary to interrupted IVC with azygos continuation. A 19-year-old man presented with a right lower limb DVT and underwent contrast-enhanced CT to assess the proximal extent of thrombus. He later developed a right ankle ulcer, likely contributed to by post-thrombotic syndrome. a Coronal CT image in the portal venous phase shows occlusive venous thrombus (arrows) in the common iliac veins and an adjacent paravertebral collateral vein (asterisk). Infrarenal and renal segments of the IVC are absent. $\mathbf{b}$ Coronal CT demonstrates the right renal vein (arrow) draining into a small caliber interrupted inferior vena cava (arrowhead). c Axial CT shows a left renal vein (asterisk) that drains into a tortuous left-sided paravertebral collateral vein (arrow). d Axial CT image with distended azygos and hemiazygos veins (arrows)

carcinoma is an additional independent risk factor for thrombogenesis [57].

Clinical presentation depends on acuity and extent of thrombosis and may vary from incidental detection on imaging, to non-specific back pain preceding symptoms of lower limb venous insufficiency, to cardiopulmonary compromise [124]. If untreated, up to $90 \%$ of patients may develop post-thrombotic syndrome, while $45 \%$ can develop severe venous claudication [118, 125]. In contrast to tumour thrombus, bland thrombus does not enhance and lacks both luminal expansion and contiguity with the mass [16]. Anticoagulation is the mainstay of treatment, and a subset of patients with acute and subacute thrombus may benefit from catheter-directed thrombolysis with or without angioplasty and stenting [119].

\section{Pseudothrombus}

Pseudothrombus or 'mixing artefact' is a potential imaging pitfall due to heterogeneous opacification of blood mimicking the appearance of a thrombus. This can be seen on both CT and MR imaging, and in the IVC is most often attributed to contrast-enhanced blood from the renal veins flowing alongside a column of unenhanced blood from the lower extremities (Fig. 23) [126]. It can also occur due to retrograde flow of contrast material due to right heart failure [59]. Delayed post-contrast imaging 70-90 s after contrast material injection allows for more uniform opacification of blood, and therefore resolution of the mixing artefact [17]. 

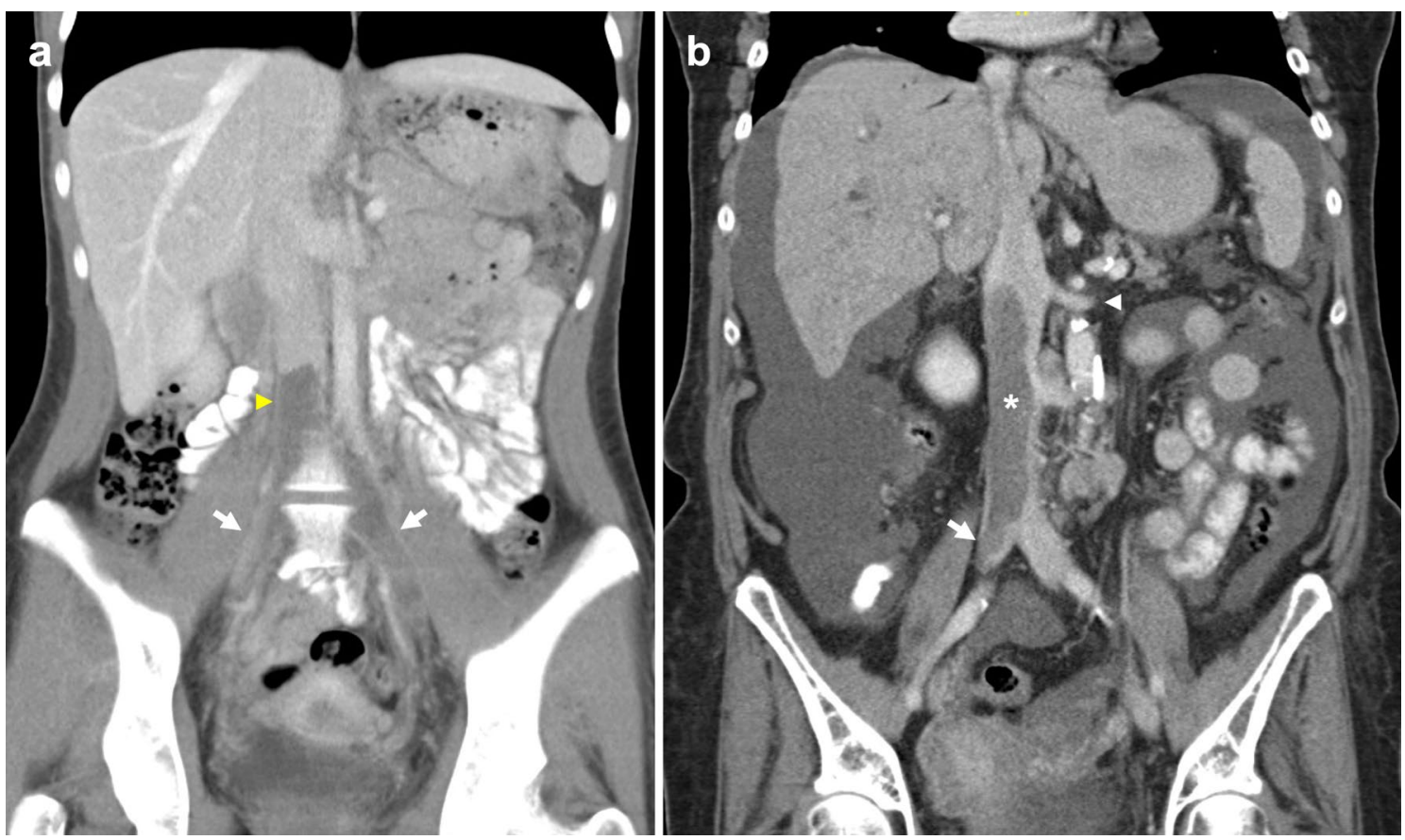

Fig. 22 IVC bland thrombosis. a A 20-year-old woman presented with an oedematous left leg and lower back pain in the context of smoking, regular oral contraceptive use and previous DVT. Contrast-enhanced coronal CT shows a non-enhancing filling defect in the infrarenal cava (arrowhead) that propagates into bilateral common iliac veins (arrows). Mild intra-abdominal fat stranding is likely secondary to thrombosis-related oedema. Thrombophilia screen was negative, and there was no evidence of malignancy or venous compression on a CT scan of the chest, abdomen and pelvis. $\mathbf{b}$ A 75-year-old woman presented with a left above knee DVT on a background of cholangiocarcinoma with metastases to the liver and left adnexa. Contrast-enhanced coronal CT demonstrates a partially occlusive non-enhancing inferior vena cava thrombus (asterisk) extending superiorly to the level of the left renal vein (arrowhead), and to the right common iliac vein (arrow) caudally
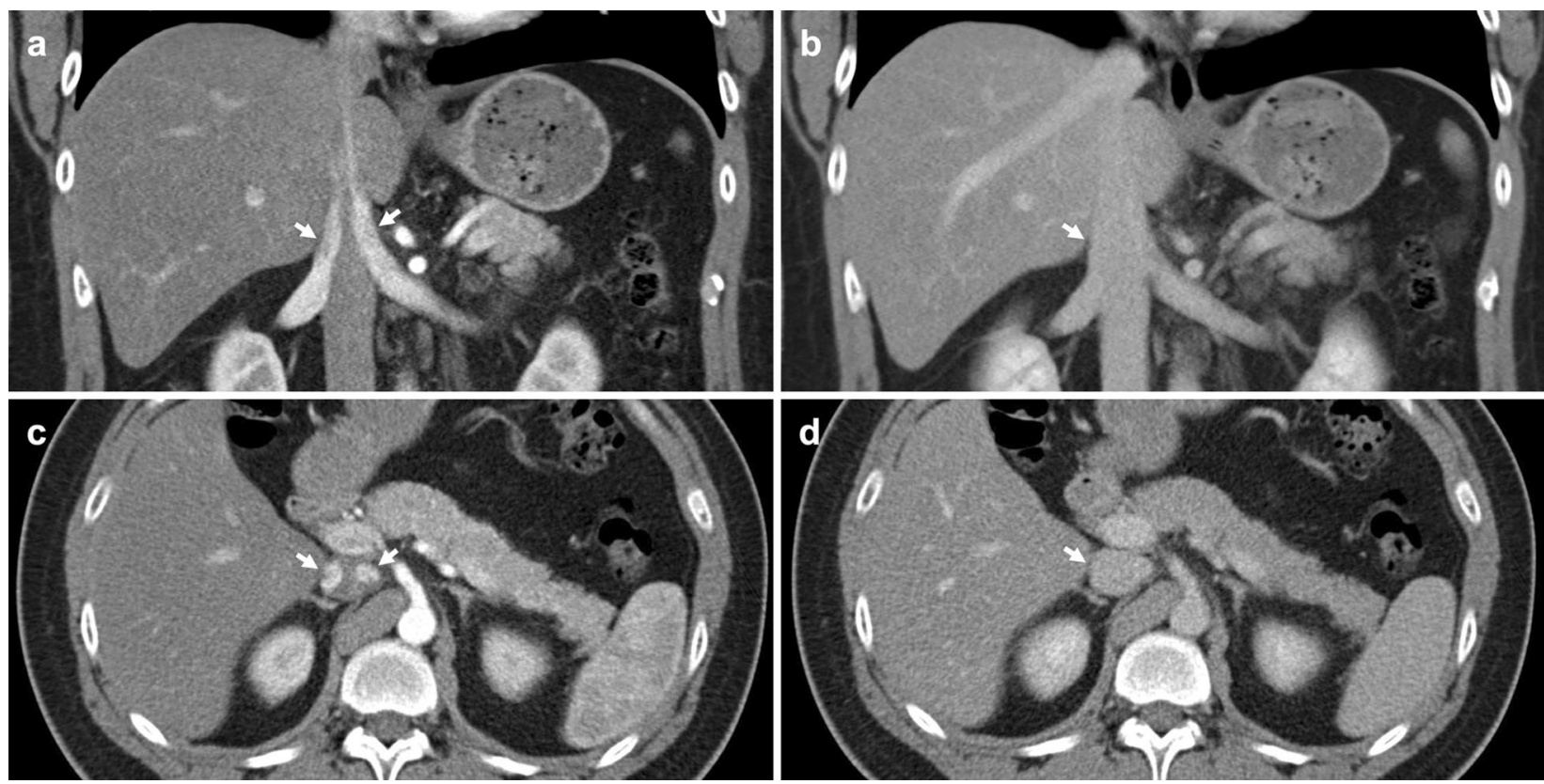

Fig. 23 IVC pseudothrombus due to mixing artefact. a,c Arterial phase CT demonstrates an apparent filling defect in the IVC attributable to contrast-enhanced blood (arrows) draining from both renal veins and running alongside a column of non-enhanced blood from the lower extremities. b,d Coronal and axial CT images of the suprarenal IVC (arrows) show resolution of the filling defect in portal venous phase 


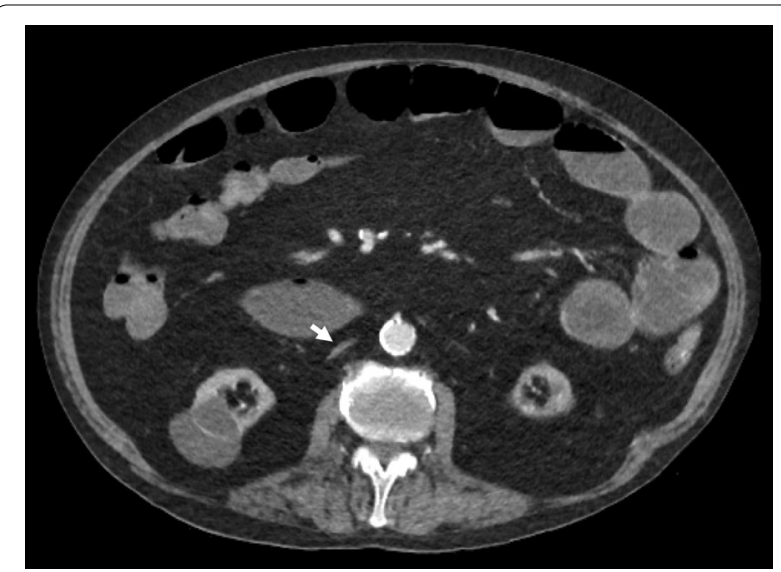

Fig. 24 Slit-like IVC from hypovolaemia. Axial-enhanced CT image demonstrates a slit-like IVC or 'flat cava'sign (arrow), consistent with the patient's clinically evident hypovolaemia following surgery

\section{Other pathologies}

A slit-like or flattened IVC may be defined as an IVC with an anteroposterior diameter less than $9 \mathrm{~mm}$ or a transverse-to-anteroposterior diameter ratio greater than 3:1 that is seen at multiple levels (Fig. 24) [127-129]. This is particularly important to recognise in the context of trauma, as it can indicate hypovolaemia or hypotension [17]. Moreover, when not involved in trauma, this sign can predict development of shock, need for aggressive resuscitation and increased mortality [127-130]. However, this should be taken with a grain of salt, as a slit-like IVC may be non-specific outside the context of trauma.
A retrospective study of approximately 500 patients without a history of trauma demonstrated that up to twothirds of patients with a 'flat cava' sign, or slit-like IVC, were clinically euvolaemic or normotensive [131].

Early opacification of the IVC can be seen in a several conditions such as congestive heart failure, aortocaval fistula, arteriovenous shunting or superior vena cava obstruction [16]. Dilation of the IVC and hepatic veins, in addition to early opacification of the IVC and hepatic veins on contrast-enhanced cross-sectional imaging, is characteristic findings of congestive hepatopathy. This can be secondary to passive congestion, most commonly secondary to cardiac disease (Fig. 25) [132]. An aortocaval fistula is an uncommon complication, most often attributed to erosion from an abdominal aortic aneurysm (Fig. 26). Other rarer causes include post-traumatic fistulisation, neoplasm and inflammatory conditions. Timely diagnosis and referral for surgical or endovascular repair are crucial for improved patient outcomes [72].

\section{Conclusion}

The IVC is an important structure that can be affected by a wide range of congenital anomalies and acquired pathologies. It is important for radiologists to be familiar with various appearances of the IVC in benign and malignant pathologies. The recognition of the anatomical variants of the IVC is also important, especially prior to intervention. Imaging also plays a key role in differentiating tumour extension from bland thrombus and in assessing extent of tumour thrombus. Such information is essential for patient care and impacts staging, surgical
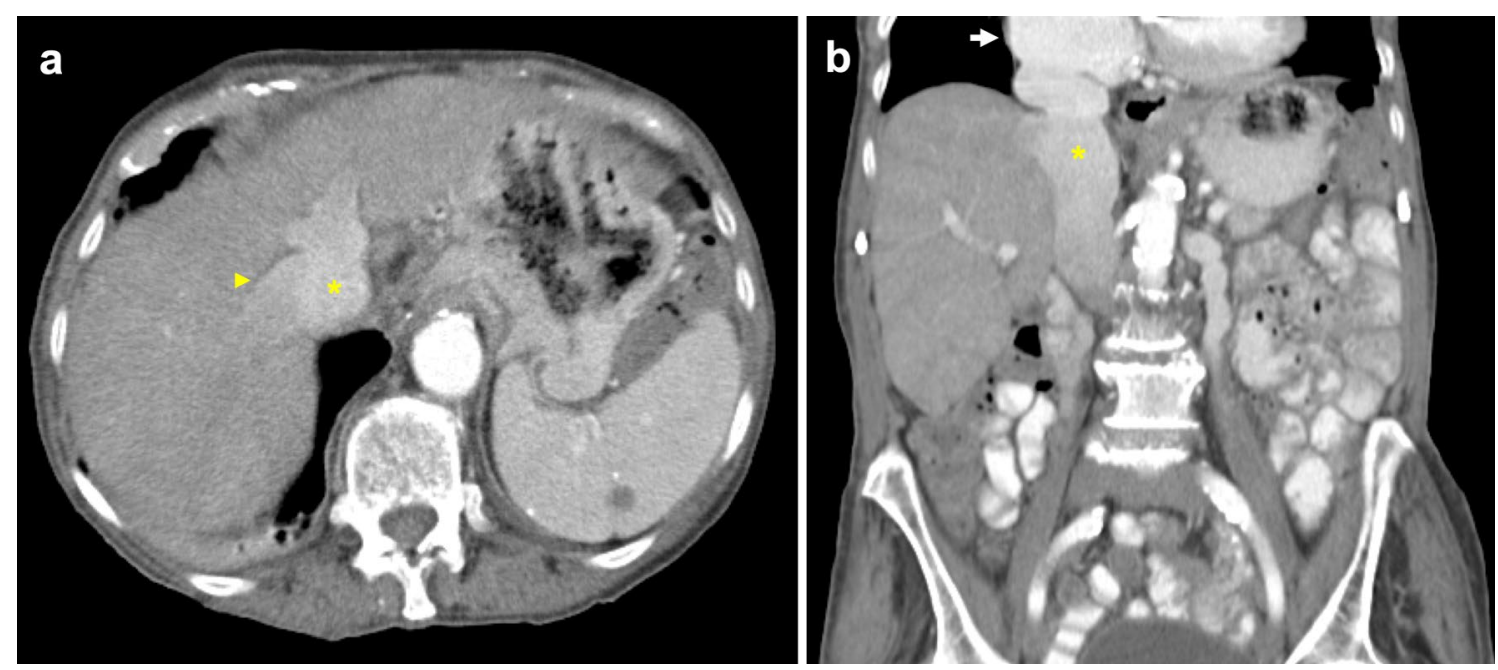

Fig. 25 Dilated IVC from heart failure. a Axial and (b) coronal contrast-enhanced CT images demonstrating dilation of the IVC (asterisk) with hepatic reflux of contrast from the right atrium with early opacification (arrowhead) in a patient with clinically evident heart failure. The cardiomegaly (arrow) is partially imaged 

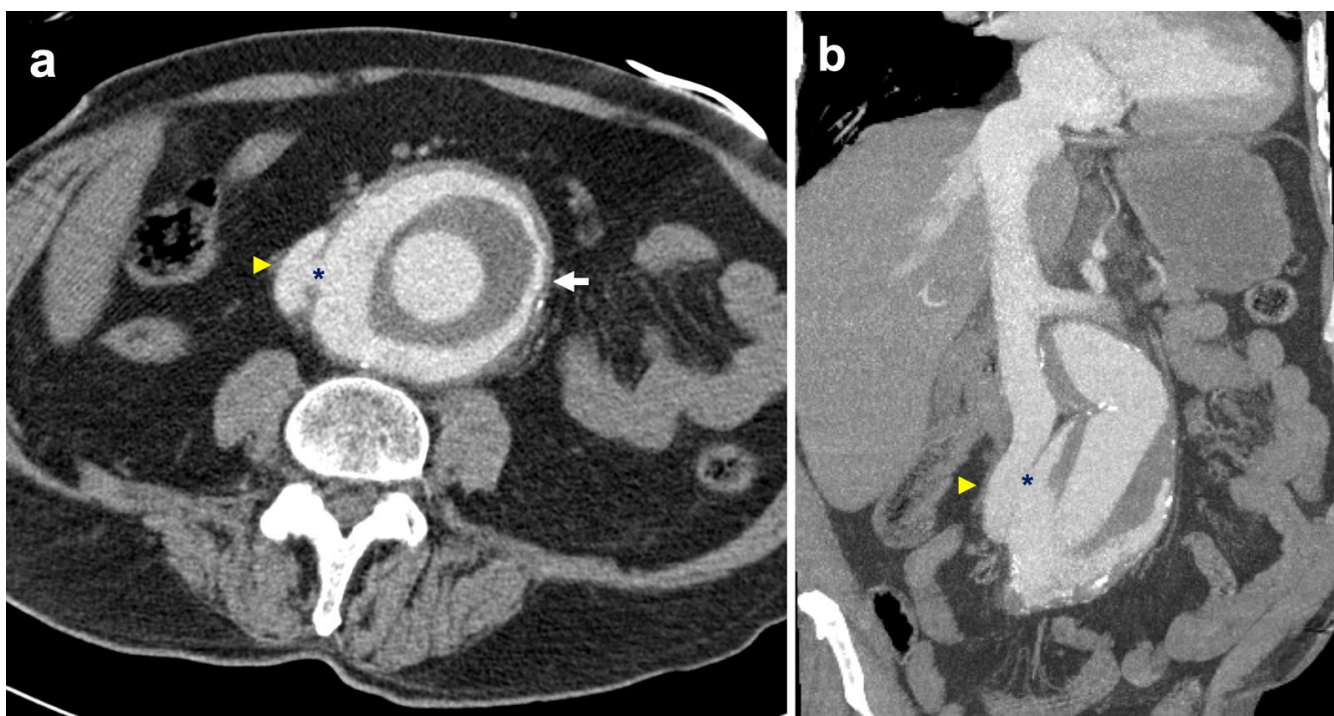

Fig. 26 Aortocaval fistula complicating abdominal aortic aneursym. a Axial and $\mathbf{b}$ coronal contrast-enhanced CT images of a fistula (asterisk) between the IVC (arrowhead) and an abdominal aortic aneurysm (arrow), with similar contrast opacification of the aneurysm sac and the IVC in the arterial phase. The abdominal aortic aneurysm contains a combination of contrast opacification and non-enhancing thrombus

planning and medical therapy. Evaluation of the IVC should form a fundamental part of a radiologist's search pattern.

\section{Abbreviations}

ACC: Adrenal cortical carcinoma; ADC: Apparent diffusion coefficient; CT: Computed tomography; DVT: Deep vein thrombosis; FDG: Flurodeoxyglucose; HCC: Hepatocellular carcinoma; HU: Hounsfield units; IVC: Inferior vena cava; MRI: Magnetic resonance imaging; NSCLC: Non-small cell lung carcinoma; PET: Positron emission tomography; RCC: Renal cell carcinoma; SPECT: Single-photon emission computed tomography; SVC: Superior vena cava; TNM: Tumournode-metastasis; VIBE: Volumetric interpolated breath-hold examination.

\section{Acknowledgements}

The authors would like to thank lam Saibaba G for creating figures depicting the embryological development of the IVC.

\section{Authors' contributions}

TS conceived the idea and structure of this review. TS, JH and JL acquired the patient images. SL drafted the manuscript. All authors were involved in critical revision. All authors read and approved the final manuscript.

\section{Funding}

Not applicable.

\section{Availability of data and materials}

Not applicable.

\section{Declarations}

Ethics approval and consent to participate

No institutional review board approval was required.

\section{Consent for publication}

Not applicable.

\section{Competing interests}

The authors declare they have no competing interests.

\section{Author details}

${ }^{1}$ Medical Imaging Department, St Vincent's Hospital Melbourne, 41 Victoria Parade, Fitzroy, VIC 3065, Australia. ${ }^{2}$ Department of Radiology, Austin Health, Heidelberg, VIC, Australia. ${ }^{3}$ Faculty of Medicine, Dentistry and Health Sciences, University of Melbourne, Parkville, VIC, Australia.

Received: 1 July 2021 Accepted: 7 August 2021

Published online: 30 August 2021

\section{References}

1. Saylisoy S, Atasoy Ç, Ersöz S, Karayalçin K, Akyar S (2005) Multislice CT angiography in the evaluation of hepatic vascular anatomy in potential right lobe donors. Diagn Interv Radiol 11(1):51-59

2. Gupta R, Gupta A, Aggarwal N (2015) Variations of gonadal veins: embryological prospective and clinical significance. J Clin Diagn Res, 9(2): AC08-10

3. Bubb K, Du Plessis M, Hage R, Tubbs RS, Loukas M (2016) The internal anatomy of the inferior vena cava with specific emphasis on the entrance of the renal, gonadal and lumbar veins. Surg Radiol Anat 38(1):107-114

4. Baniel J, Foster RS, Donohue JP (1995) Surgical anatomy of the lumbar vessels: implications for retroperitoneal surgery. J Urol 153(5):1422-1425

5. McClure CFW, Butler EG (1925) The development of the vena cava inferior in man. Am J Anat 35:331-383

6. Kellman GM, Alpern MB, Sandler MA, Craig BM (1988) Computed tomography of vena caval anomalies with embryologic correlation. Radiographics 8(3):533-556

7. Bass JE, Redwine MD, Kramer LA, Huynh PT, Harris JH Jr (2000) Spectrum of congenital anomalies of the inferior vena cava: crosssectional imaging findings. Radiographics 20(3):639-652

8. Macchi V, Parenti A, De Caro R (2003) Pivotal role of the sub-supracardinal anastomosis in the development and course of the left renal vein. Clin Anat 16(4):358-361 
9. Mayo J, Gray R, St Louis E, Grosman H, McLoughlin M, Wise D (1983) Anomalies of the inferior vena cava. AJR Am J Roentgenol 140(2):339-345

10. Tarazi M, Bashir A, Khan K, Kakani N, Murray D, Serracino-Inglott F (2020) A literature review and case series of DVT patients with absent IVC treated with thrombolysis. Ann Vasc Surg 67:521-531

11. Dougherty MJ, Calligaro KD, DeLaurentis DA (1996) Congenitally absent inferior vena cava presenting in adulthood with venous stasis and ulceration: a surgically treated case. J Vasc Surg 23(1):141-146

12. Koc Z, Oguzkurt $L$ (2007) Interruption or congenital stenosis of the inferior vena cava: prevalence, imaging, and clinical findings. Eur J Radiol 62(2):257-266

13. Lambert M, Marboeuf $P$, Midulla M et al (2010) Inferior vena cava agenesis and deep vein thrombosis: 10 patients and review of the literature. Vasc Med 15(6):451-459

14. Wax JR, Pinette MG, Fife J, Blackstone J, Cartin A (2007) Absent infrarenal inferior vena cava: an unusual cause of pelvic varices. J Ultrasound Med 26(5):699-701

15. Menezes T, Haider EA, Al-Douri F, El-Khodary M, Al-Salmi I (2019) Pelvic congestion syndrome due to agenesis of the infrarenal inferior vena cava. Radiol Case Rep 14(1):36-40

16. Kandpal H, Sharma R, Gamangatti S, Srivastava DN, Vashisht S (2008) Imaging the inferior vena cava: a road less traveled. Radiographics 28(3):669-689

17. Sheth S, Fishman EK (2007) Imaging of the inferior vena cava with MDCT. AJR Am J Roentgenol 189(5):1243-1251

18. Phillips E. (1969). Embryology, normal anatomy, and anomalies. In: Ferris EJ, Hipona FA, Kahn PC, Phillips E, Shapiro JH (eds) Venography of the inferior vena cava and its branches, Williams \& Wilkins, Baltimore, Md, pp 1-32

19. Natsis K, Apostolidis S, Noussios G, Papathanasiou E, Kyriazidou A, Vyzas $V$ (2010) Duplication of the inferior vena cava: anatomy, embryology and classification proposal. Anat Sci Int 85(1):56-60

20. Shin DS, Sandstrom CK, Ingraham CR, Monroe EJ, Johnson GE (2019) The inferior vena cava: a pictorial review of embryology, anatomy, pathology, and interventions. Abdom Radiol (NY) 44(7):2511-2527

21. Shaheen S, Alyahya KI, El Fouhil AF, et al (2021) An extremely rare complete bilateral duplication of Inferior vena cava in a male cadaver: anatomy, embryology and clinical relevance. Folia Morphol (Warsz). https://doi.org/10.5603/FM.a2021.0016

22. Petik B (2015) Inferior vena cava anomalies and variations: imaging and rare clinical findings. Insights Imaging 6(6):631-639

23. Shaha P, Garg A, Sahoo K, Kothari N, Garg P (2016) Duplication of inferior vena cava with associated anomalies: a rare case report. J Clin Diagn Res, 10(3): TD01-04

24. Chou CT, Yang AD, Hong YC, Wu HK (2006) Bilateral retrocaval ureters with IVC duplication. Abdom Imaging 31(5):596-597

25. Smith TR, Frost A (1996) Anomalous inferior vena cava associated with horseshoe kidneys. Clin Imaging 20(4):276-278

26. Shaw MBK, Cutress M, Papavassiliou V, White S, Thompson M, Sayers R (2003) Duplicated inferior vena cava and crossed renal ectopia with abdominal aortic aneurysm: preoperative anatomic studies facilitate surgery. Clin Anat 16(4):355-357

27. Evans JC, Earis J, Curtis J (2001) Thrombosed double inferior vena cava mimicking paraaortic lymphadenopathy. Br J Radiol 74(878):192-194

28. Kouroukis C, Leclerc JR (1996) Pulmonary embolism with duplicated inferior vena cava. Chest 109(4):1111-1113

29. Milani C, Constantinou M, Berz D, Butera JN, Colvin GA (2008) Left sided inferior vena cava duplication and venous thromboembolism: case report and review of literature. J Hematol Oncol 1:24

30. Sartori MT, Zampieri P, Andres AL, Prandoni P, Motta R, Miotto D (2006) Double vena cava filter insertion in congenital duplicated inferior vena cava: a case report and literature review. Haematologica, 91 (6 Suppl): ECR30

31. Mano A, Tatsumi T, Sakai H et al (2004) A case of deep venous thrombosis with a double inferior vena cava effectively treated by suprarenal filter implantation. Jpn Heart J 45(6):1063-1069

32. Smith DC, Kohne RE, Taylor FC (1992) Steel coil embolization supplementing filter placement in a patient with a duplicated inferior vena cava. J Vasc Interv Radiol 3(3):577-580
33. Sweeney J, Parikh N (2018) Inferior vena cava filter placement in a left IVC and drainage into duplicated SVC via hemiazygous continuation. Radiol Case Rep 13(2):320-323

34. Mathews R, Smith PA, Fishman EK, Marshall FF (1999) Anomalies of the inferior vena cava and renal veins: embryologic and surgical considerations. Urology 53(5):873-880

35. Wu WK, Guth CM, Mulherin JL (2020) Abdominal aortic aneurysm repair requiring left-sided inferior vena cava interposition. Ann Vasc Surg 68:573-575

36. Berry CA (2019) Oblique lumbar interbody fusion in patient with persistent left-sided inferior vena cava: case report and review of literature. World Neurosurg 132:58-62

37. Wang LH, Liu B, Wu Z et al (2011) Left transperitoneal laparoscopic partial nephrectomy in the presence of a left-sided inferior vena cava. Urology 78(2):469-473

38. d'Archambeau O, Verguts L, Myle J (1990) Congenital absence of inferior vena cava. J Belge Radiol 73(6):516-517

39. Bass JE, Redwine MD, Kramer LA, Harris JH Jr (1999) Absence of the infrarenal inferior vena cava with preservation of the suprarenal segment as revealed by CT and MR venography. AJR Am J Roentgenol 172(6):1610-1612

40. Paddock M, Robson N (2014) The curious case of the disappearing IVC: a case report and review of the aetiology of inferior vena cava agenesis. J Radiol Case Rep 8(4):38-47

41. Debing E, Tielemans Y, Jolie E, Van den Brande P (1993) Congenital absence of inferior vena cava. Eur J Vasc Surg 7(2): 201-203

42. Milner LB, Marchan R (1980) Complete absence of the inferior vena cava presenting as a paraspinous mass. Thorax 35(10):798-800

43. Ginaldi S, Chuang VP, Wallace S (1980) Absence of hepatic segment of the inferior vena cava with azygous continuation. J Comput Assist Tomogr 4(1):112-114

44. Namisaki H, Nishigami K, Murakami M, Yamamoto T, Ogata Y, Tomita A (2013) Congenital absence of inferior vena cava with azygos continuation revealed by vascular echo in a patient with pulmonary thromboembolism and deep vein thrombosis: a case report. Ann Vasc Dis 6(2):195-197

45. Winer-Muram HT, Tonkin IL (1989) The spectrum of heterotaxic syndromes. Radiol Clin North Am 27(6):1147-1170

46. Schultz CL, Morrison S, Bryan PJ (1984) Azygos continuation of the inferior vena cava: demonstration by NMR imaging. J Comput Assist Tomogr 8(4):774-776

47. Cohen MI, Gore RM, Vogelzang RL, Rochester D, Neiman HL, Crampton AR (1984) Accessory hemiazygos continuation of left inferior vena cava: CT demonstration. J Comput Assist Tomogr 8(4):777-779

48. Effler DB, Greer AE, Sifers EC (1951) Anomaly of the vena cava inferior; report of fatality after ligation. J Am Med Assoc 146(14):1321-1322

49. Mazzucco A, Bortolotti U, Stellin G, Gallucci V (1990) Anomalies of the systemic venous return: a review. J Card Surg 5(2):122-133

50. Alkhalili E, Greenbaum A, Langsfeld M et al (2016) Leiomyosarcoma of the inferior vena cava: a case series and review of the literature. Ann Vasc Surg 33:245-251

51. Hilliard NJ, Heslin MJ, Castro CY (2005) Leiomyosarcoma of the inferior vena cava: three case reports and review of the literature. Ann Diagn Pathol 9(5):259-266

52. Okada Y, Nagino M, Kamiya J, Yamamoto H, Hayakawa N, Nimura Y (2003) Diagnosis and treatment of inferior vena caval invasion by hepatic cancer. World J Surg 27(6):689-694

53. Kuehnl A, Schmidt M, Hornung HM, Graser A, Jauch KW, Kopp R (2007) Resection of malignant tumors invading the vena cava: perioperative complications and long-term follow-up. J Vasc Surg 46(3):533-540

54. Shikino K, Ohira Y, Ikusaka M (2016) Oedema and thoracoepigastric vein dilation on bilateral legs: adrenal gland tumour with inferior vena cava tumour thrombus. BMJ Case Rep

55. Gunderson CC, Parsons B, Penaroza S, Peyton MD, Landrum LM (2016) Intravenous leiomyomatosis disguised as a large deep vein thrombosis. J Radiol Case Rep 10(5):29-35

56. Mannina EM, Xiong Z, Self R, Kandil E (2014) Resection of a catecholamine-elaborating retroperitoneal paraganglioma invading the inferior vena cava. Case Rep Surg, 837054

57. Kraft C, Schuettfort G, Weil Y et al (2014) Thrombosis of the inferior vena cava and malignant disease. Thromb Res 134(3):668-673 
58. Sonin AH, Mazer MJ, Powers TA (1992) Obstruction of the inferior vena cava: a multiple-modality demonstration of causes, manifestations, and collateral pathways. Radiographics 12(2):309-322

59. Kaufman LB, Yeh BM, Breiman RS et al (2005) Inferior vena cava filling defects on CT and MRI. AJR Am J Roentgenol 185(3):717-726

60. Akin O, Dixit D, Schwartz L (2011) Bland and tumor thrombi in abdominal malignancies: magnetic resonance imaging assessment in a large oncologic patient population. Abdom Imaging 36(1):62-68

61. Alfuhaid TR, Khalili K, Kirpalani A, Haider MA, Wilson SR, Daneman A (2005) Neoplasms of the inferior vena cava-pictorial essay. Can Assoc Radiol J 56(3):140-147

62. Jenkins S, Marshall GB, Gray R (2005) Leiomyosarcoma of the inferior vena cava. Can J Surg 48(3):252-253

63. Wachtel H, Gupta M, Bartlett EK et al (2015) Outcomes after resection of leiomyosarcomas of the inferior vena cava: a pooled data analysis of 377 cases. Surg Oncol 24(1):21-27

64. Mingoli A, Cavallaro A, Sapienza P, Di Marzo L, Feldhaus RJ, Cavallari N (1996) International registry of inferior vena cava leiomyosarcoma: analysis of a world series on 218 patients. Anticancer Res 16(5B):3201-3205

65. Hartman DS, Hayes WS, Choyke PL, Tibbetts GP (1992) From the archives of the AFIP. Leiomyosarcoma of the retroperitoneum and inferior vena cava: radiologic-pathologic correlation. Radiographics 12(6): 1203-1220

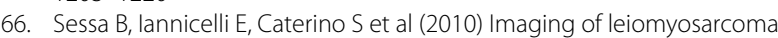
of the inferior vena cava: comparison of 2 cases and review of the literature. Cancer Imaging 10:80-84

67. Ruh J, Lang H, Paul A, Dirsch O, Broelsch CE (2006) Surgical aspects in the therapy of primary sarcoma of the vena cava. J Am Coll Surg 202(3):559-562

68. Kulaylat MN, Karakousis CP, Doerr RJ, Karamanoukian HL, O'Brien J, Peer $R$ (1997) Leiomyosarcoma of the inferior vena cava: a clinicopathologic review and report of three cases. J Surg Oncol 65(3):205-217

69. Kieffer E, Alaoui M, Piette JC, Cacoub P, Chiche L (2006) Leiomyosarcoma of the inferior vena cava: experience in 22 cases. Ann Surg 244(2):289-295

70. Nishino M, Hayakawa K, Minami M, Yamamoto A, Ueda H, Takasu K (2003) Primary retroperitoneal neoplasms: CT and MR imaging findings with anatomic and pathologic diagnostic clues. Radiographics 23(1):45-57

71. Webb EM, Wang ZJ, Westphalen AC, Nakakura EK, Coakley FV, Yeh BM (2013) Can CT features differentiate between inferior vena cava leiomyosarcomas and primary retroperitoneal masses? AJR Am J Roentgenol 200(1):205-209

72. Smillie RP, Shetty M, Boyer AC, Madrazo B, Jafri SZ (2015) Imaging evaluation of the inferior vena cava. Radiographics 35(2):578-592

73. Armstrong PJ, Franklin DP (2002) Pararenal vena cava leiomyosarcoma versus leiomyomatosis: difficult diagnosis. J Vasc Surg 36(6):1256-1259

74. Cuevas C, Raske M, Bush WH et al (2006) Imaging primary and secondary tumor thrombus of the inferior vena cava: multi-detector computed tomography and magnetic resonance imaging. Curr Probl Diagn Radiol 35(3):90-101

75. Staehler G, Brkovic D (2000) The role of radical surgery for renal cell carcinoma with extension into the vena cava. J Urol 163(6):1671-1675

76. Chen X, Li S, Xu Z et al (2015) Clinical and oncological outcomes in Chinese patients with renal cell carcinoma and venous tumor thrombus extension: single-center experience. World J Surg Oncol 13:14

77. Zini L, Destrieux-Garnier L, Leroy $X$, et al (2008) Renal vein ostium wall invasion of renal cell carcinoma with an inferior vena cava tumor thrombus: prediction by renal and vena caval vein diameters and prognostic significance. J Urol, 179(2): 450-454; discussion 454

78. Ciancio G, Manoharan M, Katkoori D, De Los SR, Soloway MS (2010) Long-term survival in patients undergoing radical nephrectomy and inferior vena cava thrombectomy: single-center experience. Eur Urol 57(4):667-672

79. Martinez-Salamanca Jl, Huang WC, Millan I et al (2011) Prognostic impact of the 2009 UICC/AJCC TNM staging system for renal cell carcinoma with venous extension. Eur Urol 59(1):120-127

80. Dunnick NR (2016) Renal cell carcinoma: staging and surveillance. Abdom Radiol (NY) 41(6):1079-1085
81. Jurado A, Romeo A, Gueglio G, Marchinena PG (2021) Current trends in management of renal cell carcinoma with venous thrombus extension. Curr Urol Rep 22(4):23

82. Kim HL, Zisman A, Han KR, Figlin RA, Belldegrun AS (2004) Prognostic significance of venous thrombus in renal cell carcinoma. Are renal vein and inferior vena cava involvement different? J Urol, 171 (2 Pt 1): 588-591

83. Neves RJ, Zincke H (1987) Surgical treatment of renal cancer with vena cava extension. Br J Urol 59(5):390-395

84. Blute ML, Leibovich BC, Lohse CM, Cheville JC, Zincke H (2004) The Mayo Clinic experience with surgical management, complications and outcome for patients with renal cell carcinoma and venous tumour thrombus. BJU Int 94(1):33-41

85. Lawrentschuk N, Gani J, Riordan R, Esler S, Bolton DM (2005) Multidetector computed tomography vs magnetic resonance imaging for defining the upper limit of tumour thrombus in renal cell carcinoma: a study and review. BJU Int 96(3):291-295

86. Zhang L, Yang G, Shen W, Qi J (2007) Spectrum of the inferior vena cava: MDCT findings. Abdom Imaging 32(4):495-503

87. Psutka SP, Boorjian SA, Thompson RH et al (2015) Clinical and radiographic predictors of the need for inferior vena cava resection during nephrectomy for patients with renal cell carcinoma and caval tumour thrombus. BJU Int 116(3):388-396

88. Welch TJ, LeRoy AJ (1997) Helical and electron beam CT scanning in the evaluation of renal vein involvement in patients with renal cell carcinoma. J Comput Assist Tomogr 21(3):467-471

89. Adams LC, Ralla B, Bender YY et al (2018) Renal cell carcinoma with venous extension: prediction of inferior vena cava wall invasion by MRI. Cancer Imaging 18(1):17

90. Lee IJ, Chung JW, Kim HC et al (2009) Extrahepatic collateral artery supply to the tumor thrombi of hepatocellular carcinoma invading inferior vena cava: the prevalence and determinant factors. J Vasc Interv Radiol 20(1):22-29

91. Kaneko T, Nakao A, Nomoto S, Endo T, Itoh S, Takagi H (1996) Intracaval endovascular ultrasonography for preoperative assessment of retrohepatic inferior vena cava infiltration by malignant hepatic tumors. Hepatology 24(5):1121-1127

92. Chang JY, Ka WS, Chao TY, Liu TW, Chuang TR, Chen LT (2004) Hepatocellular carcinoma with intra-atrial tumor thrombi. A report of three cases responsive to thalidomide treatment and literature review. Oncology, 67(3-4): 320-326

93. Wang Y, Yuan L, Ge RL, Sun Y, Wei G (2013) Survival benefit of surgical treatment for hepatocellular carcinoma with inferior vena cava/right atrium tumor thrombus: results of a retrospective cohort study. Ann Surg Oncol 20(3):914-922

94. Chun YH, Ahn SH, Park JY et al (2011) Clinical characteristics and treatment outcomes of hepatocellular carcinoma with inferior vena cava/ heart invasion. Anticancer Res 31(12):4641-4646

95. Xia Y, Zhang J, Ni X (2020) Diagnosis, treatment and prognosis of hepatocellular carcinoma with inferior vena cava/right atrium tumor thrombus. Oncol Lett 20(4):101

96. Wilson K, Guardino J, Shapira O (2001) Pulmonary tumor embolism as a presenting feature of cavoatrial hepatocellular carcinoma. Chest 119(2):657-658

97. Catalano OA, Choy G, Zhu A, Hahn PF, Sahani DV (2010) Differentiation of malignant thrombus from bland thrombus of the portal vein in patients with hepatocellular carcinoma: application of diffusionweighted MR imaging. Radiology 254(1):154-162

98. Lee HA, Park S, Seo YS, Yoon WS, Shin IS, Rim CH (2020) Surgery versus external beam radiotherapy for hepatocellular carcinoma involving the inferior vena cava or right atrium: A systematic review and meta-analysis. J Hepatobiliary Pancreat Sci

99. Lee HA, Rim CH (2020) Efficacy of local treatments for hepatocellular carcinoma involving the inferior vena cava and/or right atrium. J Hepatocell Carcinoma 7:435-446

100. Sharma E, Dahal S, Sharma P et al (2018) The characteristics and trends in adrenocortical carcinoma: a United States population based study. J Clin Med Res 10(8):636-640

101. Ng L, Libertino JM (2003) Adrenocortical carcinoma: diagnosis, evaluation and treatment. J Urol 169(1):5-11 
102. Sturgeon C, Shen WT, Clark OH, Duh QY, Kebebew E (2006) Risk assessment in 457 adrenal cortical carcinomas: how much does tumor size predict the likelihood of malignancy? J Am Coll Surg 202(3):423-430

103. Elsayes KM, Mukundan G, Narra VR et al (2004) Adrenal masses: mr imaging features with pathologic correlation. Radiographics 24(Suppl 1):S73-86

104. Bharwani N, Rockall AG, Sahdev A et al (2011) Adrenocortical carcinoma: the range of appearances on CT and MRI. AJR Am J Roentgenol 196(6):W706-714

105. Shin YR, Kim KA (2015) Imaging features of various adrenal neoplastic lesions on radiologic and nuclear medicine imaging. AJR Am J Roentgenol 205(3):554-563

106. Slattery JM, Blake MA, Kalra MK et al (2006) Adrenocortical carcinoma: contrast washout characteristics on CT. AJR Am J Roentgenol 187(1):W21-24

107. Libe R, Borget I, Ronchi CL et al (2015) Prognostic factors in stage III-IV adrenocortical carcinomas (ACC): an European Network for the Study of Adrenal Tumor (ENSAT) study. Ann Oncol 26(10):2119-2125

108. Whalen RK, Althausen AF, Daniels GH (1992) Extra-adrenal pheochromocytoma. J Urol 147(1):1-10

109. Maher ER, Eng C (2002) The pressure rises: update on the genetics of phaeochromocytoma. Hum Mol Genet 11(20):2347-2354

110. Ahmad S, Cathy D, Sheikh M, Sweeney P (2009) Retroperitoneal extraadrenal paraganglioma: a rare but important diagnosis. Ir J Med Sci 178(2):211-214

111. Mannelli M, lanni L, Cilotti A, Conti A (1999) Pheochromocytoma in Italy: a multicentric retrospective study. Eur J Endocrinol 141(6):619-624

112. Bravo EL, Tagle R (2003) Pheochromocytoma: state-of-the-art and future prospects. Endocr Rev 24(4):539-553

113. O'Riordain DS, Young Jr WF, Grant CS, Carney JA, Van Heerden JA (1996) Clinical spectrum and outcome of functional extraadrenal paraganglioma. World I Surg, 20(7): 916-921; discussion 922

114. Baez JC, Jagannathan JP, Krajewski K et al (2012) Pheochromocytoma and paraganglioma: imaging characteristics. Cancer Imaging 12:153-162

115. Blake MA, Kalra MK, Maher MM et al (2004) Pheochromocytoma: an imaging chameleon. Radiographics 24(Suppl 1):S87-99

116. Timmers HJ, Taieb D, Pacak K (2012) Current and future anatomical and functional imaging approaches to pheochromocytoma and paraganglioma. Horm Metab Res 44(5):367-372

117. Lenders JW, Duh QY, Eisenhofer G et al (2014) Pheochromocytoma and paraganglioma: an endocrine society clinical practice guideline. J Clin Endocrinol Metab 99(6):1915-1942

118. McAree BJ, O'donnell ME, Fitzmaurice GJ, Reid JA, Spence RA, Lee B (2013) Inferior vena cava thrombosis: a review of current practice. Vasc Med 18(1): 32-43
119. Alkhouli M, Morad M, Narins CR, Raza F, Bashir R (2016) Inferior vena cava thrombosis. JACC Cardiovasc Interv 9(7):629-643

120. Pozzi A, El Lakis MA, Chamieh J, Carbonell BB, Villa F (2016) The typical presentation spectrum of deep vein thrombosis associated with inferior vena cava malformations. Thrombosis 2016:4965458

121. Obernosterer A, Aschauer M, Schnedl W, Lipp RW (2002) Anomalies of the inferior vena cava in patients with iliac venous thrombosis. Ann Intern Med 136(1):37-41

122. Ruggeri M, Tosetto A, Castaman G, Rodeghiero F (2001) Congenital absence of the inferior vena cava: a rare risk factor for idiopathic deepvein thrombosis. Lancet 357(9254):441

123. Chee YL, Culligan DJ, Watson HG (2001) Inferior vena cava malformation as a risk factor for deep venous thrombosis in the young. Br J Haematol 114(4):878-880

124. Kraft C, Hecking C, Schwonberg J, Schindewolf M, Lindhoff-Last E, Linnemann B (2013) Patients with inferior vena cava thrombosis frequently present with lower back pain and bilateral lower-extremity deep vein thrombosis. Vasa 42(4):275-283

125. Kahn SR (2006) The post-thrombotic syndrome: the forgotten morbidity of deep venous thrombosis. J Thromb Thrombolysis 21(1):41-48

126. Vogelzang RL, Gore RM, Neiman HL, Smith SJ, Deschler TW, Vrla RF (1985) Inferior vena cava CT pseudothrombus produced by rapid armvein contrast infusion. AJR Am J Roentgenol 144(4):843-846

127. Anand T, van Sonnenberg E, Gadani K, Skinner R (2016) A snapshot of circulation failure following acute traumatic injury: the expansion of computed tomography beyond injury diagnosis. Injury 47(1):50-52

128. Takada H, Hifumi T, Yoshioka $\mathrm{H}$ et al (2018) Initial inferior vena cava diameter predicts massive transfusion requirements in blunt trauma patients: a retrospective cohort study. Am J Emerg Med 36(7):1155-1159

129. Li Y, Zhang LY, Wang Y, Zhang WG (2013) The flatness index of inferior vena cava is useful in predicting hypovolemic shock in severe multipleinjury patients. J Emerg Med 45(6):872-878

130. Dipti A, Soucy Z, Surana A, Chandra S (2012) Role of inferior vena cava diameter in assessment of volume status: a meta-analysis. Am J Emerg Med, 30(8): 1414-1419

131. Eisenstat RS, Whitford AC, Lane MJ, Katz DS (2002) The "flat cava" sign revisited: what is its significance in patients without trauma? AJR Am J Roentgenol 178(1):21-25

132. Wells ML, Fenstad ER, Poterucha JT et al (2016) Imaging Findings of Congestive Hepatopathy. Radiographics 36(4):1024-1037

\section{Publisher's Note}

Springer Nature remains neutral with regard to jurisdictional claims in published maps and institutional affiliations.

\section{Submit your manuscript to a SpringerOpen ${ }^{\circ}$ journal and benefit from:}

- Convenient online submission

- Rigorous peer review

- Open access: articles freely available online

- High visibility within the field

- Retaining the copyright to your article

Submit your next manuscript at $\boldsymbol{\nabla}$ springeropen.com 